\title{
Preparing the New Phase of Argo: Scientific Achievements of the NAOS Project
}

\author{
Pierre-Yves Le Traon 1,2*, Fabrizio D’Ortenzio ${ }^{3}$, Marcel Babin $^{4}$, Edouard Leymarie ${ }^{3}$, \\ Claudie Marec ${ }^{4,5,6}$, Sylvie Pouliquen ${ }^{1}$, Virginie Thierry ${ }^{7}$, Cecile Cabanes ${ }^{6,7}$, \\ Hervé Claustre ${ }^{3}$, Damien Desbruyères ${ }^{7}$, Leo Lacour ${ }^{4,5}$, Jose-Luis Lagunas ${ }^{4,5,8}$, \\ Guillaume Maze ${ }^{7}$, Herle Mercier ${ }^{7}$, Christophe Penkerc' ${ }^{3}$, Noe Poffa ${ }^{1}$, Antoine Poteau ${ }^{3}$, \\ Louis Prieur ${ }^{3}$, Virginie Racapé 7 , Achim Randelhoff 4,5 , Eric Rehm ${ }^{4,5}$, \\ Catherine Marie Schmechtig ${ }^{9}$, Vincent Taillandier ${ }^{3}$, Thibaut Wagener ${ }^{10}$ and \\ Xiaogang Xing ${ }^{11}$
}

OPEN ACCESS

Edited by: Laura Lorenzoni,

National Aeronautics and Space Administration (NASA), United States

Reviewed by:

Bozena Wojtasiewicz, Oceans and Atmosphere (CSIRO),

Australia

Borja Aguiar-González, University of Las Palmas de Gran Canaria, Spain

*Correspondence:

Pierre-Yves Le Traon pierre.yves.le.traon@ifremer.fr; pierre-yves.letraon@mercatorocean.fr

Specialty section: This article was submitted to Ocean Observation,

a section of the journal Frontiers in Marine Science

Received: 29 June 2020 Accepted: 14 September 2020 Published: 14 October 2020

Citation:

Le Traon P-Y, D'Ortenzio F, Babin M, Leymarie E, Marec $C$, Pouliquen S, Thierry V, Cabanes C, Claustre $H$, Desbruyères $D$, Lacour $L$, Lagunas J-L, Maze G, Mercier H, Penkerc'h C, Poffa N, Poteau A, Prieur $L$, Racapé $V$, Randelhoff $A$, Rehm E, Schmechtig CM, Taillandier $V$, Wagener $T$ and $X$ ing $X$ (2020) Preparing the New Phase of Argo: Scientific Achievements of the NAOS Project.

Front. Mar. Sci. 7:577408. doi: 10.3389/fmars.2020.577408
${ }^{1}$ Ifremer, Plouzané, France, ${ }^{2}$ Mercator Ocean International, Ramonville-Saint-Agne, France, ${ }^{3}$ CNRS-INSU, Laboratoire d'Océanographie de Villefranche, Sorbonne Université, Villefranche-Sur-Mer, France, ${ }^{4}$ UMI 3376 Takuvik, Joint International Laboratory, Département de Biologie et Québec-Océan, Université Laval, Québec, QC, Canada, ${ }^{5}$ Centre National de la Recherche Scientifique, Paris, France, ${ }^{6}$ CNRS, IRD, Unité Mixte de Service 3113, IUEM, Univ. Brest, Plouzané, France, ${ }^{7}$ CNRS, Ifremer, IRD, Laboratoire d'Océanographie Physique et Spatiale (LOPS), IUEM, Univ. Brest, Plouzané, France, ${ }^{8}$ Recherche et Développement pour la Défense Canada - Centre de Recherches de l'Atlantique, Dartmouth, NS, Canada, ${ }^{9}$ CNRS, Observatoire des Sciences de l'Univers Ecce Terra, Sorbonne Université, Paris, France, ${ }^{10}$ CNRS, IRD, MIO UM 110, Aix Marseille Univ., Université de Toulon, Marseille, France, ${ }^{11}$ State Key Laboratory of Satellite Ocean Environment Dynamics, Second Institute of Oceanography, Ministry of Natural Resources, Hangzhou, China

Argo, the international array of profiling floats, is a major component of the global ocean and climate observing system. In 2010, the NAOS (Novel Argo Observing System) project was selected as part of the French "Investissements d'Avenir" Equipex program. The objectives of NAOS were to consolidate the French contribution to Argo's core mission (global temperature and salinity measurements down to $2000 \mathrm{~m}$ ), and also to develop the future generation of French Argo profiling floats and prepare the next phase of the Argo program with an extension to the deep ocean (Deep Argo), biogeochemistry (BGC-Argo) and polar seas. This paper summarizes how NAOS has met its objectives. The project significantly boosted France's contribution to Argo's core mission by deploying more than 100 NAOS standard Argo profiling floats. In addition, NAOS deployed new-generation floats as part of three scientific experiments: biogeochemical floats in the Mediterranean Sea, biogeochemical floats in the Arctic Ocean, and deep floats with oxygen sensors in the North Atlantic. The experiment in the Mediterranean Sea, launched in 2012, implemented and maintained a network of BGC-Argo floats at basin scale for the first time. The 32 BGC-Argo floats deployed and about 4000 BGC profiles collected have vastly improved characterization of the biogeochemical and ecosystem dynamics of the Mediterranean. Meanwhile, experiments in the Arctic and in the North Atlantic, starting in 2015 and deploying 20 Arctic BGC floats and 23 deep floats, have provided unique observations on biogeochemical cycles in the Arctic and deep-water masses, as well as ocean circulation variability in the North Atlantic. NAOS has therefore paved the way to the new operational phase of the Argo program in France that includes BGC and Deep Argo extensions. The objectives and characteristics of this new phase of Argo-France are discussed in the conclusion.

Keywords: profiling floats, deep ocean, biogeochemistry, Mediterranean Sea, Arctic, Atlantic, Argo 


\section{INTRODUCTION}

Argo is an international array of about 4000 profiling floats that measure temperature and salinity throughout the deep global oceans, down to $2000 \mathrm{~m}$ (Riser et al., 2016; Roemmich et al., 2019). Argo is the first-ever global, in situ ocean observing network in the history of oceanography, providing an essential complement to satellite systems, for deeper understanding of the role of the ocean in the Earth's climate and for predictions on evolutions of the ocean, weather and climate.

France has been playing an important role in the international Argo program since its inception in the late 90's. France accounts for slightly less than $10 \%$ of the international effort by deploying about 65 floats per year, and is a key contributor to the Argo datamanagement system. Indeed, through Ifremer, France operates one of the two Global Data Assembly Centers (GDACs) as well as the French DAC that processes float data deployed by France and from other European countries. Through a public/private partnership between Ifremer and the SME nke instrumentation, France has emerged as a European leader in the development of Argo equipment (Provor and Arvor floats). France has also established the North Atlantic Argo Regional Center (ARC) and hosts the international Argo Information Center (AIC) as part of the JCOMMOPS structure. Furthermore, France leads the Euro-Argo European research infrastructure that organizes and federates European contributions to Argo. Euro-Argo evolved in 2011 into a sustained long-term European organization and legal structure (Euro-Argo ERIC).

The French contribution to Argo (Argo-France) is organized through the Coriolis partnership that gathers the main French institutions involved in ocean observing (Cerema, CNES, Ifremer, INSU, IPEV, IRD, Météo-France, SHOM). Argo-France is part of the French Ministry of Research's national roadmap on large research infrastructures (TGIR). At a regional scale, Argo-France is supported by the IUEM and Villefranche sur Mer Observatories (IUEM and OOV OSU).

In 2010, the 10-year NAOS (Novel Argo Observing System) project was selected as part the French "Investissements d'Avenir" Equipex program. The objectives of NAOS were to consolidate France's contribution to the Argo core mission (global temperature and salinity measurements down to $2000 \mathrm{~m}$ ), and also to develop the future generation of French Argo profiling floats and prepare the next phase of the Argo program with an extension to the deep ocean (Deep Argo), biogeochemistry (BGC-Argo) and polar seas (e.g., Roemmich et al., 2019; Claustre et al., 2020). NAOS was established through a partnership between Ifremer, UPMC (now Sorbonne Université), CNRS, IUEM, Shom, nke instrumentation and CLS.

Float technology improvements aimed at: developing a deep (4000 m) float, a new BGC float for R\&D applications, as well as a BGC float for deployments in Arctic areas; assessing a new density and absolute-salinity optical sensor; improving the reliability of standard Argo floats and reducing their costs; and improving satellite-transmission performance (Argos, Iridium). The project benefited from and built on a European Research Council (ERC) advanced grant (Remocean) that was obtained by
LOV laboratory (UPMC/CNRS) to work on the development of a biogeochemical component for Argo.

To consolidate the French contribution to Argo's core mission, 10-15 standard Argo floats were deployed per year from 2012 to 2019. In parallel, new-generation floats were deployed as part of three scientific experiments: biogeochemical floats in the Mediterranean Sea, biogeochemical floats in the Arctic Ocean, and deep floats with oxygen sensors in the North Atlantic. These pilot areas were chosen for their particular relevance to European research by furthering understanding on the main physical and biogeochemical processes in the different Mediterranean bioregions, monitoring water formation and transformation in the North Atlantic, and exploring the Arctic basin and the coupling between physics and biology.

A companion paper describes the technological developments carried out as part of NAOS, including at-sea validation (André et al., 2020). The present paper focuses on results from the three scientific experiments. It also summarizes the contribution of NAOS to the core Argo array and associated data-management and scientific activities.

The paper is organized as follows: Section "Contribution to the Core Argo Program" deals with the contribution of NAOS to the core Argo array. Sections "Biogeochemical floats in the Mediterranean Sea," "Biogeochemical Floats in the Arctic Ocean," and "Deep floats with oxygen sensors in the North Atlantic" summarize results from the three scientific experiments in the Mediterranean Sea, the Arctic Ocean and the North Atlantic. Main conclusions and perspectives for the French Argo program are presented in section "Perspectives and Conclusion."

\section{CONTRIBUTION TO THE CORE ARGO PROGRAM}

At the outset of the Argo program, France opted to make a nominal contribution of 65 floats per year: about 50 floats from Ifremer and 15 floats from Shom. Through the Euro-Argo ERIC agreements, France proposed to augment its long-term contribution from 65 to 80 floats per year to reach about a quarter of the European effort and $10 \%$ of the global effort. The floats purchased as part of NAOS accordingly increased France's contribution to Argo by 15 floats per year from 2012 to 2017. Altogether, 101 floats were purchased: 30 in 2012-2013, 37 in 2014-2015 and 34 in 2016-2017. The deployments started in late 2012 and the 101st float was deployed in September 2019. Their data were processed by the Coriolis data centre and provided to Argo International, to the Copernicus Marine Service (Le Traon et al., 2019), and more widely to the research and operational oceanography communities. These floats were deployed in various oceans (Figure 1): North and South Atlantic, South Pacific, Gulf of Guinea, Gulf of Bengal, Mediterranean Sea, Greenland Sea or Baffin Bay. They were mainly deployed from French or international research vessels during scientific cruises or transits ( $85 \%$ of deployments) but also from opportunity ships such as commercial or sailing boats. In the case of scientific deployments, floats were assigned on the basis of a scientific evaluation, in the framework of the annual LEFE/GMMC call 


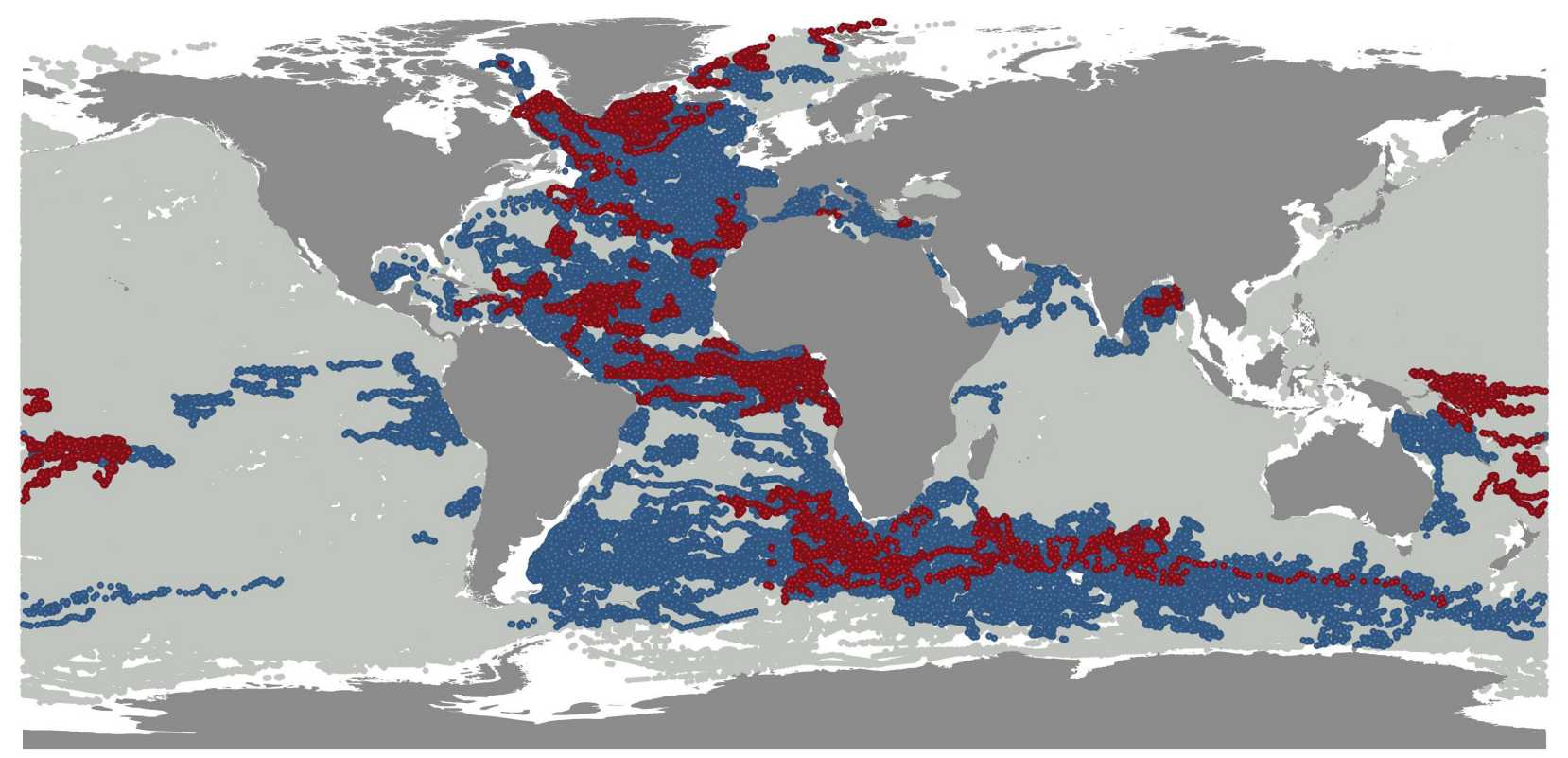

FIGURE 1 | Over 1 million Argo profiles have been acquired since late 2012. Gray points: all Argo observations. Blue points: Argo-France observations. Red points: NAOS Core Argo observations.

for proposals ${ }^{1}$. Their latest positions range from latitudes $55^{\circ} \mathrm{S}$ to $83^{\circ} \mathrm{N}$, reflecting France's broad contribution to the international Argo program in the global ocean.

In terms of the total number of acquired Argo profiles, it is worth noting that the deployment of the first NAOS standard Argo float coincided almost exactly with the one-millionth profile milestone achieved by the Argo program in late 2012. More than 1 million Argo profiles later (the second-millionth profile milestone was proclaimed in late 2018), a quick glance at the distribution of the 101 NAOS float observations shows that these floats have provided the community with more than 10000 profiles, which represents $1 \%$ of all Argo observations and 10\% of the French contribution, the latter making up $10 \%$ of the international contribution to Argo.

All NAOS core Argo floats are of the Arvor model manufactured by nke instrumentation. Over the duration of the NAOS project, the Arvor model has benefited from several improvements (André et al., 2020), including hardware and software upgrades. New mission capacities have been added and Iridium communication (fitting 14 of the latest 2017 floats) has allowed a higher sampling of the water column as well as a more versatile configuration of floats through downlink transmission. This has proved to be a real asset on some deployments where it has been possible to finely adjust the float mission to suit scientific needs at the outset (e.g., higher frequency cycling) before it has been set back to a standard Argo mission (10-day cycle) when the float has left the area of interest, usually after a few weeks. In December 2019, almost half (45/101) of the 101 floats were still active and most of the floats had reached their nominal number of 150-180 cycles ( $>4$ years) for a typical 10-day Argo sampling

${ }^{1}$ http://www.mercator-ocean.fr/en/science-publications/gmmc/ scheme with Argos transmission (see André et al., 2020). Floats equipped with Iridium communication have a higher lifetime expectancy than Argos floats (due to more efficient satellite communication), with an expected number of 225 cycles before the end of their battery life ( $>6$ years). It is however too early to draw up at-sea statistics on the expected lifetime of the NAOSgeneration Arvor floats. Indeed, none of the floats programmed on standard Argo cycles and equipped with Iridium has reached the end of their battery life yet (the first deployments of NAOS Iridium Arvor floats took place in mid-2016).

NAOS improvements have also led to the implementation of an Ice Sensing Algorithm (ISA) on the standard Arvor, thus allowing deployments in previously unsampled areas such as the Greenland Sea or the Baffin Bay, where some floats deployed have been able to survive under seasonal ice.

Ifremer, taking advantage of the expertise it has developed within NAOS, has also collaborated with the Euro-Argo ERIC to set up a suite of tools that allow at-sea monitoring of the European Argo fleet and of the national Argo fleets. A first prototype was made available in 2017 and has since been upgraded to provide Argo users with an advanced web-based monitoring tool ${ }^{2}$.

All NAOS floats have been distributed in the new Argo format, V3.1, developed by Argo International, that allows the distribution of Iridium T\&S floats as well as BGC and Deep floats. The processing chain developed within NAOS has been upgraded and made available to the international community ${ }^{3}$. This chain also implements the Argo recommendations for BGC float processing in real time.

${ }^{2}$ https://www.euro-argo.eu/Activities/Coordination/European-Fleet-Monitoring ${ }^{3}$ http://dx.doi.org/10.17882/45589 
France's ocean and climate research communities are strongly involved in Argo. Since the beginning of Argo, an original partnership between Mercator Ocean and Coriolis was set up to coordinate the interfaces between Argo-France, operational oceanography and research communities. Over the past 10 years, the French research community has contributed more than 400 Argo-related internationally refereed publications. Data from NAOS floats feed these research activities thanks to longer time series and improved sampling. Such research covers a broad range of topics including global sea-level variations (e.g., Cazenave et al., 2014; Dieng et al., 2017), ocean-heat and salt-content variations (e.g., Von Schuckmann et al., 2016), meridional circulation and deep convection (e.g., Piron et al., 2017), tropical dynamics (e.g., Cravatte et al., 2017), large-scale circulation (e.g., Sévellec et al., 2017), eddy dynamics (e.g., Capuano et al., 2018), satellite validation (e.g., Boutin et al., 2018), modeling and data assimilation (e.g., Turpin et al., 2016; Artana et al., 2018; Lellouche et al., 2018).

\section{BIOGEOCHEMICAL FLOATS IN THE MEDITERRANEAN SEA}

\section{Rationale}

In the framework of NAOS, a specific and dedicated study was conducted on the BGC-Argo component of Argo. A BGC-Argo float is an Argo profiling float equipped with biogeochemical sensors for chlorophyll, dissolved oxygen and nitrate concentrations, backscattering coefficients and irradiance. At the beginning of NAOS (2010), the BGC-Argo network was still in a preliminary phase. The technology related to the new biogeochemical sensors was already stable, but most studies at the time were conducted on the basis of a very limited number of floats (Gruber et al., 2007; Boss et al., 2008; Johnson et al., 2010). What was still lacking was a conclusive assessment of the simultaneous and multi-annual use of BGC-Argo floats as a network, in anticipation of a global array. Furthermore, the quality control methodologies for Argo biogeochemical variables (considered a fundamental prerequisite for implementing a global array) were still under development.

For these reasons, one of the objectives of the NAOS BGCArgo component was to deploy and maintain a pilot array of BGC-Argo floats at the scale of an ocean basin, and to contribute to the development and implementation of an efficient data stream for BGC-Argo parameters.

The Mediterranean Sea was selected to carry out the BGCArgo pilot test, on the basis of several scientific and logistic considerations. Despite its limited surface, the Mediterranean Sea is characterized by complex ocean dynamics (MalanotteRizzoli et al., 2014), composed of three thermohaline circulations. The three cells are forced by dense water formation, which occurs in specific and well localized areas. In these areas, the resulting water mixing generates an upwelling of nutrients from their deep reservoir, inducing weak-to-intense phytoplankton spring blooms, which locally attenuates the strong and general oligotrophy of the basin (Siokou-Frangou et al., 2010). Within a relatively limited area, the Mediterranean Sea thus shows puzzling large-scale circulation and a wide panel of contrasting biogeochemical regimes, therefore making it an ideal playground for a BGC-Argo array pilot test.

Moreover, the Mediterranean Sea has received renewed interest from the scientific community at both French and European levels (De Madron et al., 2013; Malanotte-Rizzoli et al., 2014). Scientific advancements in the last decades paved the way for a completely new approach to Mediterranean physical and biogeochemical research, based on integrated observing systems, dedicated modeling efforts, and more importantly in this context, the massive utilization of autonomous platforms. A dedicated 10year-long program (MERMEX), focusing on the Mediterranean biogeochemical response to climate change, was funded (De Madron et al., 2013), rallying together French and Mediterranean (i.e., Italian, Greek, German, Turkish, Israeli) scientists.

For both NAOS and MERMEX, one of the main scientific objectives was to identify and explain the interactions between physical circulation and phytoplankton distribution, in both oligotrophic and blooming areas. The interactions between the two projects were extremely fruitful: on the one hand, the NAOS project was nurtured by a stimulating environment for analyzing and interpreting BGC-Argo data; on the other hand, the MERMEX community benefited from novel technology providing physical-biogeochemical observations at a panMediterranean scale and over the long term.

In 2011, 30 BGC-Argo floats (Leymarie et al., 2013) were funded and acquired for the NAOS project. Their implementation and deployment plans, profiling strategies and performance statistics are described in D'Ortenzio et al. (2020) and only briefly outlined here. Among the 30 acquired floats, 27 were deployed in two successive waves (in 2012 and 2015), 14 have been recovered and 5 have been refurbished and redeployed, giving a total of 32 deployments. Among the remaining 9 floats, 5 experienced critical damages and 4 are ready for future deployments. At the end of 2019, 9 floats were still operational and 11 were definitively lost (Figure 2). The network gathered more than 3900 profiles, with floats having a mean lifetime of about 2.5 years. The deployment plan, formulated by a working group of Mediterranean experts (D'Ortenzio et al., 2012), was established by considering satellite-derived oceancolor bioregionalization (D'Ortenzio and d'Alcala, 2009) as the main framework for selecting the areas in which to launch floats. Operating on the assumption that bioregions reflect the internal mechanisms of physical-biological interactions and that they can be considered homogenous for ocean dynamics (at least on a seasonal scale), the NAOS BGC-Argo floats were distributed on the basis of 1-2 per bioregion. In agreement with the roadmap, the floats' sampling strategy (i.e., parking depth and sampling frequency) was set to maintain the buoys in the bioregion of deployment for as long as possible. Numerical simulations (described in D'Ortenzio et al., 2020) indicated an optimal parking depth of $1000 \mathrm{~m}$ and a sampling frequency modulated on the basis of the satellite phenology of each bioregion.

Since 2010, more than 20 peer-reviewed papers have been published around NAOS BGC-Argo observations. They can roughly be classified into three main groups: (1) papers contributing to the development of a global BGC-Argo network, 


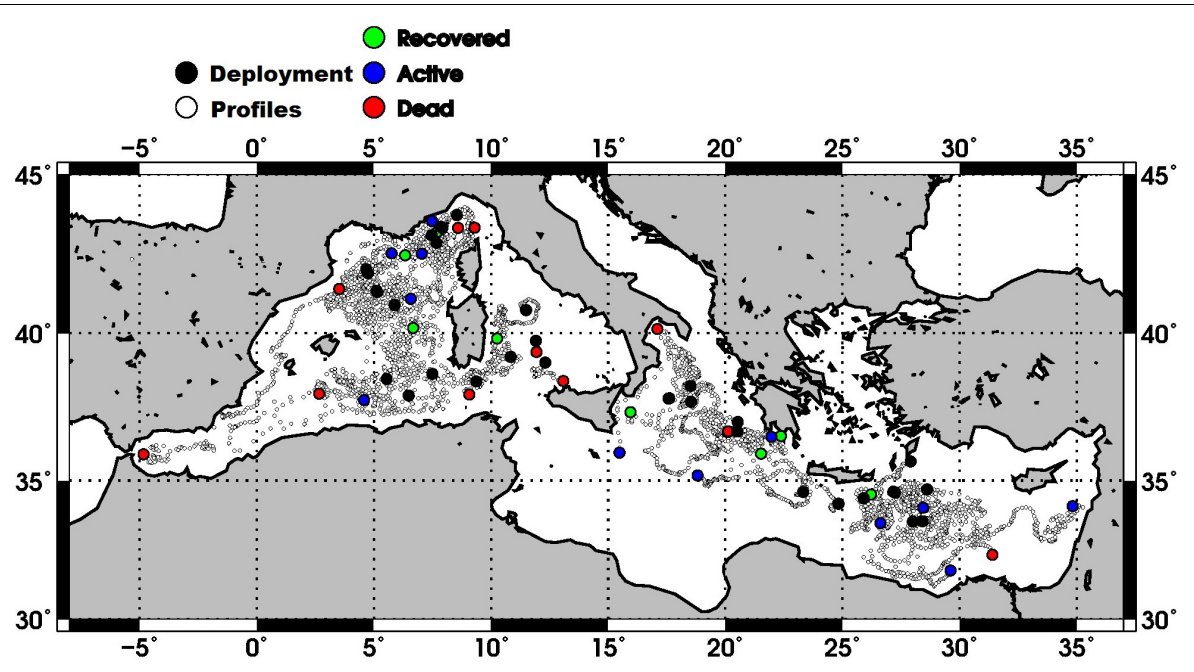

FIGURE 2 | Geographical locations of the BGC-Argo profiles of the NAOS Mediterranean network. White dots indicate the positions of the profiles, black points the locations of deployments. The last obtained profile is indicated in color: blue point for active floats, red for the dead, green for the recovered (see D'Ortenzio et al., 2020 for more details).

comprising algorithmic improvements and quality control issues; (2) papers focusing on the functioning of the Mediterranean Sea, for the most in collaboration with the MERMEX community; (3) papers assessing the global characteristics of biogeochemical parameters, where NAOS data represented the Mediterranean specificities. In the next section, a synthesis of achievements by the NAOS BGC-Argo network is given for each of these topics.

\section{Contribution to the Development of a Global BGC-Argo Array}

Technological advances have not played a substantial part in the BGC-Argo activity of NAOS, mainly because the platform (Provor-CTS4 equipped with bio-optical sensors) was already available at the beginning of the project (Leymarie et al., 2013). In the framework of the development of a global array, the NAOS project contributed mostly to improvements in Quality Control (QC) methods. During the NAOS project, the BGC-Argo community organized regular and international meetings [for the most included in the Argo Data Management Team (ADMT) events $\left.^{4}\right]$ to propose and discuss methods and organization of BGC-Argo QC. NAOS participants were strongly involved in this activity, which is summarized in the technical reports produced by the BGC-Argo ADMT (Schmechtig et al., 2015; Johnson et al., 2018; Schmechtig et al., 2018).

In parallel, specific analyses were conducted on the performances of biogeochemical sensors. Roesler et al. (2017) analyzed the calibration of the WetLab ECO-Puck fluorometers (with which most BGC-Argo floats were equipped, to measure Chlorophyll concentration) to identify possible regional variability of the chlorophyll-to-fluorescence ratio. Authors highlighted the specific behaviors of Mediterranean waters, largely on the basis of NAOS BGC-Argo data. More recently, Bittig et al. (2019) reviewed the latest advancements in QC

${ }^{4}$ http://www.argodatamgt.org and deployment best practices for BGC-Argo floats. NAOS knowhow contributed to this synthesis, in particular with regard to deployment protocols and also the acquisition and processing of ancillary data required for QC. In this way, Taillandier et al. (2018) described the different protocols tested during the second wave of NAOS float deployments. They also proposed a protocol for the recovery of BGC-Argo floats, emphasizing the role of recoveries of still-operational floats (a relatively rare event, although possible in the Mediterranean Sea) in QC methods and the evaluation of sensor performance after long deployments. In addition, Mignot et al. (2019) proposed a method for assessing observational errors in BGC-Argo data, by combining in situ observations and model simulations.

Novel Argo Observing System has also contributed to building the use of BGC-Argo observations in ocean data assimilation systems such as the ones developed as part of the Copernicus Marine Service (Le Traon et al., 2019). Cossarini et al. (2019) have developed numerical methods to assimilate BGC-Argo data (for the most part collected by NAOS floats) in a physicalbiogeochemical coupled modeling platform of the Mediterranean Sea, whereas Terzić et al. (2019) have used the same dataset to enhance representation of the propagation of sunlight in operational bio-optical models.

\section{Contribution to the Understanding of Mediterranean Biogeochemistry}

As mentioned above, BGC-Argo activity was strongly tied to international efforts to improve characterization of Mediterranean physical-biogeochemical dynamics, as organized under the MERMEX program (De Madron et al., 2011). Focusing on Mediterranean areas where deep convection and phytoplankton blooms are systematically observed, NAOS represented the BGC-Argo component of MERMEX, furnishing unprecedented data to the scientific community. 
In the North Western Mediterranean Sea, 6 research cruises were conducted during 2012-2013 and 6 NAOS floats were deployed at the same time. The observational system was complemented by two moorings and more than 30 glider missions (Estournel et al., 2016). In this context, the mechanisms generating and sustaining the deep convection of winter 2013 and the consequent phytoplankton bloom were exceptionally well elucidated (Testor et al., 2018), thanks to the combination of an adapted sampling strategy of BGC-Argo floats and glider missions. The unique collection of biogeochemical observations from autonomous platforms (in particular, nutrient and chlorophyll concentrations obtained from NAOS BGC-Argo floats) over a complete annual cycle allowed us to identify the forcing factors controlling the intense phytoplankton bloom in the North Western Mediterranean in 2013 (Mayot et al., 2017a). The observations of NAOS BGC-Argo floats provided data to interpolate between the six oceanographic cruises conducted in the area, revealing an unprecedented picture of physicalbiological interactions. Mayot et al. (2017b) extended the analysis on a multi-annual scale, by also investigating the response of phytoplankton communities to the variable forcing factors. Furthermore, BGC-Argo observations were used to initialize and validate physical-biogeochemical coupled models in the North Western Mediterranean region. Models were shown to soundly reproduce the biogeochemical cycles (Kessouri et al., 2017, 2018).

In a pan-Mediterranean context, NAOS BGC-Argo float datasets have been analyzed to identify large-scale biogeochemical characteristics of the basin, which were generally poorly assessed because of a critical lack of pertinent data. De Fommervault et al. (2015a) thus investigated the large-scale distribution of nitrate in the Mediterranean, by comparing time-series of BGC-Argo floats along an East-West gradient. They also characterized the seasonal evolution of nitracline in the Mediterranean's four main sub-basins, thanks to the unprecedented temporal resolution of the database of nitrate profiles collected by the first wave of NAOS BGC-Argo floats. By systematically analyzing chlorophyll concentration profiles obtained from the NAOS BGC-Argo array, Lavigne et al. (2015) and Barbieux et al. (2019) assessed the spatio-temporal distribution of Deep Chlorophyll Maxima (DCM), clarifying its seasonal variability in particular.

\section{Contribution to Assessments of Global Characteristics of Biogeochemical Parameters}

Although limited to the Mediterranean Sea, NAOS BGCArgo data have been repeatedly used in studies aiming to analyze global characteristics of biogeochemical fields. In this way, Organelli et al. (2017) revisited global ocean biooptical behaviors, on the basis of the unique collection of irradiance profiles obtained by BGC-Argo floats. Thanks to NAOS observations, a specific section of the Mediterranean, characterized by a well-known bio-optical anomaly (Volpe et al., 2007), was included in this study. Similarly, Barbieux et al. (2018) characterized the global ocean variability of backscattering coefficients, generally used as a proxy of organic carbon and systematically sampled by BGC-Argo floats. The authors assessed the regional variability of backscattering coefficients, emphasizing the peculiar characteristics of the Mediterranean Sea. NAOS BGC-Argo data were also used in the development of advanced statistical methods to augment the quantity and quality of information obtained from floats. Neural network algorithms were developed and applied to enhance the spatial resolution of biogeochemical fields (Sauzède et al., 2015) and to generate parameters still unavailable directly (at least for the majority of Argo BGC floats), such as $\mathrm{pH}, \mathrm{pCO}_{2}$, and nitrate concentrations (Sauzède et al., 2016, 2017; Bittig et al., 2018c).

\section{The Step Forward: Interannual Variability}

After 7 years of operations, the NAOS Mediterranean array has provided an exceptional dataset on the physical and biogeochemical dynamics of the basin. The collected data have already been intensively exploited and the NAOS Mediterranean pilot array has been internationally acknowledged as a successful example of the potential of a global BGC-Argo array (Biogeochemical-Argo Planning Group, 2016). The network is still operational and its data offer further avenues of research yet to be explored. For example, the interannual variability of Mediterranean biogeochemical cycles - clearly one of the potential applications of the existing BGC-Argo network calls for investigation.

A first attempt to analyze interannual variability of NAOS BGC-Argo data in the Mediterranean is presented below. We focus specifically on the North Western Mediterranean region, on which several papers have been published using NAOS BGCArgo data (see above), and for which the density of collected profiles is particularly high.

In the North Western Mediterranean region, additional BGCArgo floats on top of the NAOS fleet have been deployed under the responsibility of the Argo-France (GMMC) and ArgoItaly programs. These floats have the same sensor configuration as NAOS BGC floats (although most of them have no $\mathrm{NO}_{3}$ sensor). Corresponding datasets were processed using the same methods as for the NAOS floats. When NAOS data are combined with the other float data, the number of collected profiles over the period 2013-2019 comes to 1472, with $545 \mathrm{NO}_{3}$ profiles (see map in Figure 3).

The merging of all the data from the North Western Mediterranean region (the so-called bloom bioregion defined by Mayot et al. (2017a)) generated time series of Mixed Layer Depth (MLD, computed by BGC-Argo T/S data following D'Ortenzio et al., 2012) and of Chlorophyll concentration in the 0-300 $\mathrm{m}$ layer and the surface (Figures 3,4). Time series of the depth of isolines of $\mathrm{NO}_{3}$ concentrations were also produced. We selected the isoline of $7 \mu$ mole $/ \mathrm{kg}$ as a proxy of the deep stock, and the isoline of $1.5 \mu \mathrm{mole} / \mathrm{kg}$ as a proxy of the nutrientdepleted layer. The well-known recurrent phytoplankton blooms (Figures 3, 4, upper panel) are well observed during the winterto-spring transition (Mayot et al., 2017b). Interannual variability is particularly evident in the intensity of blooming events, with a decreasing magnitude for the absolute maximum of the surface and the integrated (between 0 and $300 \mathrm{~m}$ ) chlorophyll from 2012 to 2019. 


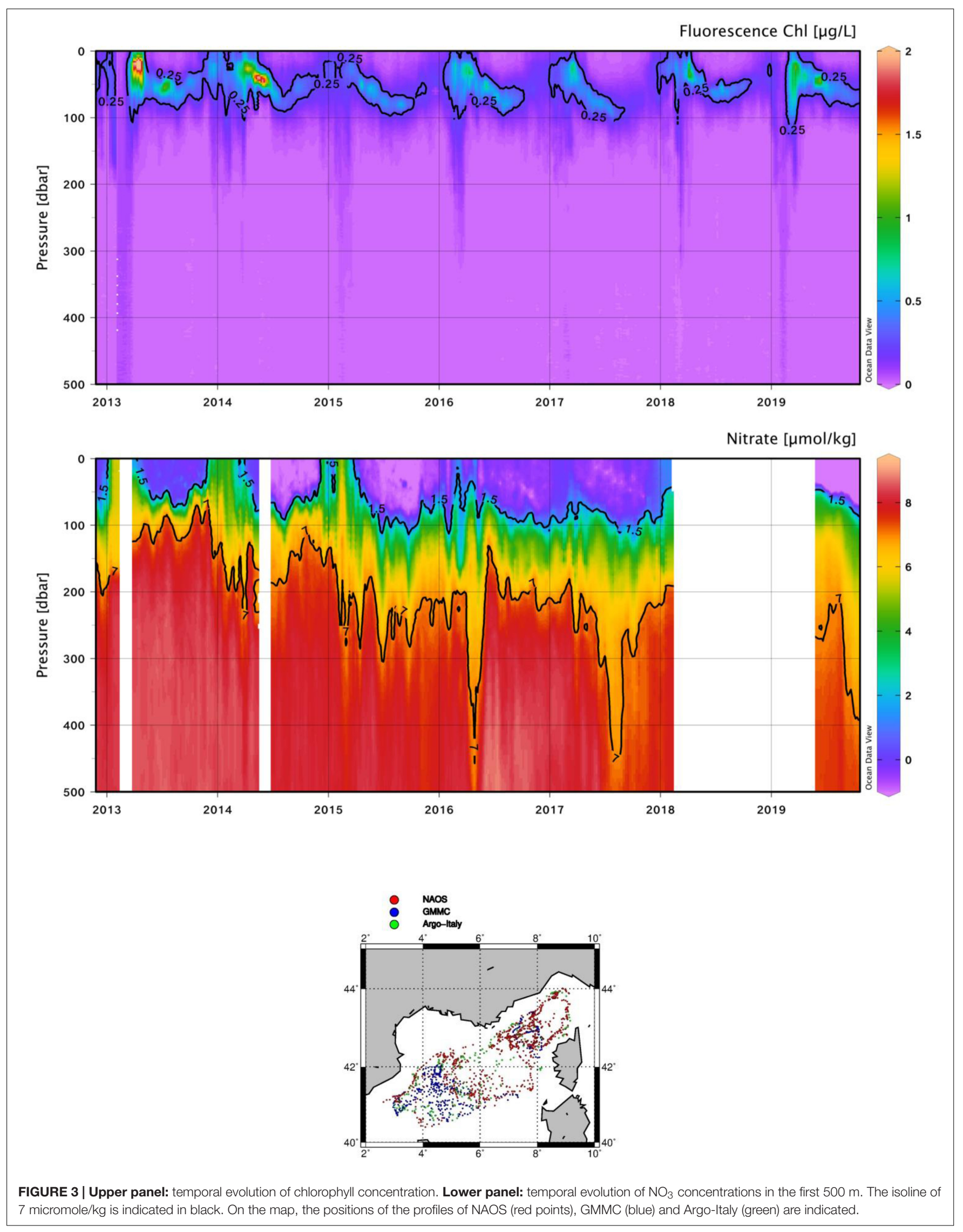




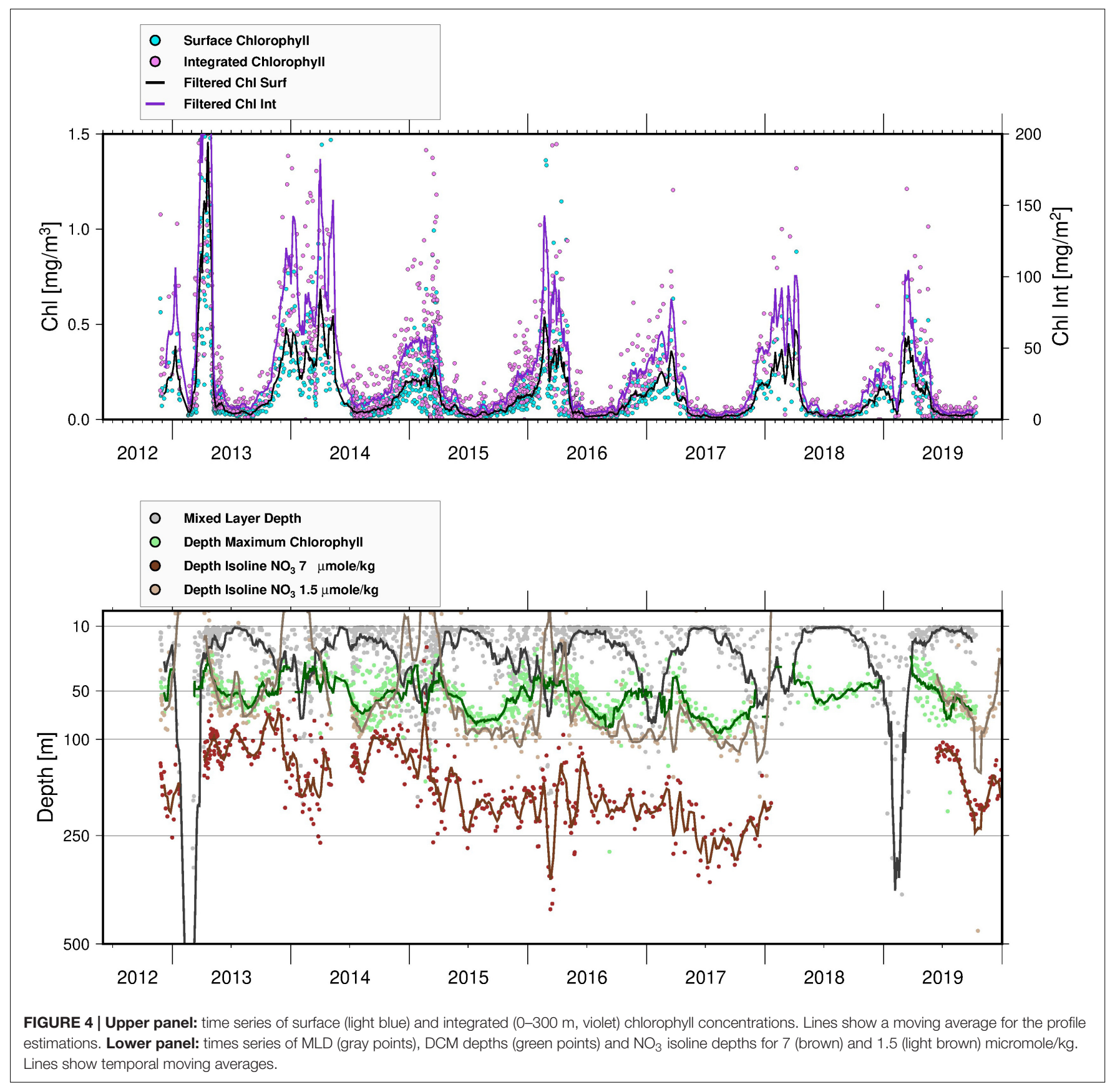

The intensity of mixing is also highly variable interannually (Figure 4, lower panel). In winter 2012-2013, an event of MLD greater than $700 \mathrm{~m}$ was captured (Testor et al., 2018; Prieur et al., 2020). A MLD deeper than $400 \mathrm{~m}$ was also observed during winter 2018-2019. For the other years, the MLD was generally shallower, with mean values rarely exceeding $100 \mathrm{~m}$. MLDs greater than $400 \mathrm{~m}$, as observed in the 2012-2013 and 2018-2019 winters, can provoke different and contrasting responses: an intense bloom in 2012-2013 and a weak episode of chlorophyll increase in 2018-2019. Following on from these contrasts, the bloom observed in 2013-2014 period - the second most important event in the series in terms of magnitude - is paralleled by a MLD not exceeding $100 \mathrm{~m}$.

The vertical distribution of $\mathrm{NO}_{3}$ and its time evolution closely follow the water-column characteristics, showing that nutrient stocks are relatively shallow in the area, and that injection of nitrate in the surface layers is possible even in the case of relatively low MLD deepening. Spring surface $\mathrm{NO}_{3}$ concentrations observed by BGC-Argo in the North Western Mediterranean are generally not zero and were unusually high in 2013, 2014, and 2015 (and in 2018, although less clearly because of missing data). Consequently, and as expected, phytoplankton concentrations during the winter-to-spring transition were 
generally high (i.e., showing blooming conditions). The injection of $\mathrm{NO}_{3}$ in the surface and the associated phytoplankton growth do not seem, however, to be directly dependent on the mixing intensity (i.e., the maximum depth reached by the mixed layer). For example, an increase of $\mathrm{NO}_{3}$ in the surface was observed in 2015 or in 2016, although the MLD rarely exceeded a depth of $200 \mathrm{~m}$ in these years.

On the other hand, the intensity of winter mixing appears to impact on $\mathrm{NO}_{3}$ concentrations in sub-surface layers for the rest of the following year. Excluding the periods characterized by $\mathrm{NO}_{3}$ increase following MLD deepening, the surface waters are completely depleted of $\mathrm{NO}_{3}$ for most of the year. Generally, the depth of the depleted layer is approximately $100 \mathrm{~m}$ for all the time series, except during the winter-to-spring period when the vertical distribution of $\mathrm{NO}_{3}$ in the first $500 \mathrm{~m}$ appears anomalous and an uplift of the $1.5 \mathrm{NO}_{3}$ isoline is observed (i.e., $75-80 \mathrm{~m}$ ). During these periods, the $\mathrm{NO}_{3}$ concentrations characterizing the deep stock (i.e., approx. 7 micromole/kg for the NW Mediterranean) are observed at shallower depths than in other years. In other words, the periods following the strong mixing events in the winters of 2013 and 2019 are characterized by a subsurface distribution of $\mathrm{NO}_{3}$ different from all the other sampled years.

As already postulated by D'Ortenzio et al. (2014) (through analysis of $\mathrm{NO}_{3}$ profiling floats during the year 2012-2013), deep mixing events are therefore not critical for inducing phytoplankton blooms at the surface, as $\mathrm{NO}_{3}$ concentrations at the subsurface are always relatively high. Even relatively shallow MLDs allow upper layers to be refueled with nutrients. In this context, analysis of the NAOS interannual time series offers another element. Deep mixing events (as in the winters of 2013 and 2019) induce a dramatic redistribution of $\mathrm{NO}_{3}$ throughout the water column. The main consequence is the presence of $\mathrm{NO}_{3}$ concentrations at depths shallower than those observed during the years without deep mixing. This anomalous uplift of $\mathrm{NO}_{3}$ following a deep MLD event seems to have an impact on the characteristics of Deep Chlorophyll Maximum (DCM, Figure 4). For most years, the DCM deepens progressively after the MLD annual maxima, roughly following the 1.5 micromole $/ \mathrm{kg}$ isoline (as already recognized by Barbieux et al., 2019). The DCM is finally destroyed when the MLD reaches its layer, during the following autumn. Anomalously, in the period following the 2013 bloom, and up to fall 2014, the depth of the DCM was quite stable with the DCM intensity (i.e., chlorophyll values at maxima) decreasing only weakly over time.

Assuming the spatial and temporal representativeness of the network (see D'Ortenzio et al., 2020, for a comprehensive discussion of this issue), interannual analysis of BGC-Argo profiles in the North Western Mediterranean indicates that MLD intensity is not the primary factor controlling springbloom intensity. The area's large-scale conditions (Prieur et al., 2020) induce a sufficiently significant uplift of $\mathrm{NO}_{3}$ isolines to sustain phytoplankton growth, even in the case of relatively weak mixing. However, the complete vertical redistribution of $\mathrm{NO}_{3}$ that occurs after deep-mixing events modifies the characteristics of the DCM for the rest of the year: conditions more favorable for phytoplankton growth develop close to the surface and DCM depths remain shallow for most of the following spring and summer.

\section{Conclusion}

The NAOS BGC-Argo experiment in the Mediterranean Sea was highly successful, from technological, logistical and scientific points of view. Technologically, platforms and sensors were operationally tested on long-term deployments: very few sensors experienced failure and float statistics are close to those for the global BGC-Argo array (D'Ortenzio et al., 2020), which is an excellent result in a marginal sea. The NAOS fleet met the initial requirement of continuous BGC monitoring of a basin-scale area for 7 years, with an average float lifetime of 2.5 years. Logistically, NAOS tested different ways to develop and maintain the network, acquiring important knowhow for the construction of a global BGC-Argo array. The high number of float recoveries led to substantial reductions in network costs, allowing a third wave of deployments that was not planned at the beginning of the project. Recoveries data as well as ancillary information collected at recoveries also provided unique information on data quality and sensor performance (e.g., Mignot et al., 2019). Recoveries were certainly facilitated by the reduced size of the Mediterranean; they required, in addition, organization, logistics and an improved float technology. D'Ortenzio et al. (2020) provides a wider discussion on the benefits and the disadvantages of the recoveries. Part of the experiment's success is also due to the strong collaboration with Med-Argo (Poulain et al., 2007), in charge of coordinating Mediterranean Argo activity. Scientifically, close collaboration with the international community of the MERMEX project generated an extremely fruitful synergy, which resulted in an high number of publications about the physical-biogeochemical dynamics of the Mediterranean Sea (in addition to the papers already cited, see for example Lavigne et al., 2013; Prieur et al., 2014; De Fommervault et al., 2015b; Houpert et al., 2016; Bosse et al., 2017; Xing et al., 2017). Additionally, NAOS BGC-Argo activity contributed to the assessment of operational QC methods, in the international framework of the ADMT. Interactions with operational centers were not limited to the QC data stream. Important collaborations with physicalbiogeochemical operational modelers recurred throughout the NAOS lifetime. This activity was conducted in collaboration with the Italian OGS group (Cossarini et al., 2019; Terzić et al., 2019) and with Mercator Ocean International, in particular to define metrics for data-model validation.

\section{BIOGEOCHEMICAL FLOATS IN THE ARCTIC OCEAN}

\section{The Scientific Context of a Pilot Study in Baffin Bay}

Climate change has triggered fundamental modifications to marine biotopes in the Arctic Ocean. For instance, the decrease in the extent of the icepack during summer has led to a $30 \%$ increase in pan-Arctic primary production (PP) over the past two decades (Arrigo and Van Dijken, 2015). One prominent element 
of PP in the Arctic Ocean is the phytoplankton spring bloom (PSB) that develops around the ice edge, both under sea ice and in open waters: accounting for much of the annual PP, this PSB is generally associated with both large energy transfer to higher trophic levels and export of carbon at depth (e.g., Randelhoff et al., 2019). To determine the fate of the PSB and related Arctic ecosystem features in a context of profound changes, it is necessary to develop a mechanistic understanding of this recurrent event, i.e., how exactly it is controlled by the physical and chemical properties of sea ice and the upper water column. To study the dynamics of PSBs, year-long high-frequency time series of phytoplankton phenology and its drivers are required. In the AO, BGC-Argo floats are a complementary tool to remote sensing and oceanographic cruises, useful for studying the dynamics of the PSB as controlled by sea-ice dynamics, vertical mixing, light and nutrients. The development of a new generation of floats (Pro-Ice) for operation in icy waters was carried out as part of the NAOS project. The fleet of Pro-Ice floats was co-funded by NAOS and the Canadian Foundation for Innovation (CFI). The first deployments of BGC-Argo floats in Baffin Bay debuted in 2016. They were performed as part of a NAOS pilot experiment, within the programmatic framework of the Green Edge research project ${ }^{5}$. The main objectives were to study Arctic PSBs.

\section{Materials and Methods \\ Features of the Pro-Ice Floats}

For the Arctic pilot study, 21 Pro-Ice floats, equipped with a biogeochemical payload and adapted to navigate in icy waters, were prepared for deployment in Baffin Bay. Pro-Ice floats are manufactured by the French company nke instrumentation using third-party electronics and were developed in the framework of NAOS (see André et al., 2020). They belong to the Provor-CTS5 class, an extension of the Provor-CTS4 (Leymarie et al., 2018; André et al., 2020; D'Ortenzio et al., 2020), and have been adapted to operate in ice-covered seas.

Pro-Ice BGC floats are equipped with a Sea-Bird SBE41 CTD (conductivity-temperature-depth) unit, an Aanderaa 4330 oxygen optode mounted on a $30-\mathrm{cm}$ stalk, a WET Labs ECO Triplet for the observation of chlorophyll $a$ fluorescence, CDOM (colored dissolved organic matter) fluorescence, and particle backscattering at $700 \mathrm{~nm}\left(\mathrm{~b}_{\mathrm{bp}}\right)$, as well as a Satlantic SUNA V2 sensor for nitrate. They are also fitted with a Satlantic OCR504 radiometer measuring irradiance at three wavelengths (412, $490,555 \mathrm{~nm}$ ) and quantum irradiance over the photosynthetically available radiation (PAR) range $(400-700 \mathrm{~nm})$. This payload gathers five of the six core Biogeochemical Argo variables: oxygen, nitrate, chlorophyll $a$, suspended particles, downwelling irradiance and $\mathrm{pH}$.

An ice-covered ocean presents a real challenge for Argo floats that must surface for geo-localization and to use satellite networks for data transmission and command reception (Riser et al., 2016). Therefore, technical adjustments are required to make the floats as operational as possible in the Arctic Ocean, in particular with essential ice-detection systems to allow them to

${ }^{5}$ http://www.greenedgeproject.info/ surface only in favorable ice-free conditions (see details in André et al., 2020). When not surfacing, the Pro-Ice stores data in a nonvolatile memory until satellite communications are resumed.

\section{Strategy for Deployments in the Icy Waters of Baffin Bay}

The deployment of floats in Baffin Bay (BB) implied navigational challenges in terms of bathymetry, ice coverage and circulation. Possible trajectories of floats were simulated to optimize the localization of the deployment areas and to ensure as much as possible that floats stayed in the Baffin Bay throughout their lifetimes. The cyclonic circulation in the area and the Baffin Current tend to eject any drifting object (including icebergs) from Baffin Bay along the west side of Davis Strait. Simulations of trajectories were achieved using the Ariane tool (Blanke et al., 19996) that permits offline calculation of streamlines from model velocity fields. The velocity fields on a $1 / 4^{\circ}$ grid came from the Canadian CONCEPTS Global IceOcean Prediction System (GIOPS, Smith et al., 2016). Based on these simulated trajectories (Figure 5), two main dropping zones that avoided ultimate ejection were selected with a bathymetry largely above $1000 \mathrm{~m}$ : the BB2 ArcticNet station $\left(72^{\circ} 45^{\prime} 060 \mathrm{~N}\right.$ $\left.67^{\circ} 0 \mathrm{~W}\right)$ at the very center of the Baffin Bay cyclonic gyre and southeast of the Baffin Bay $\left(69^{\circ} 30 \mathrm{~N} 61^{\circ} \mathrm{W}\right)$ within the 2016 Green Edge cruise area (GE; Randelhoff et al., 2019). These zones are presented in Figure 6. Trajectory simulations were combined with observations from ice charts (climatology and real-time charts) for safe deployments and navigation. MODIS chlorophyll $a$ concentration images were used as well for the choice of location and deployment period relevant to the ice-edge PSB. Mid-July was the most favorable period for the deployments.

In terms of float programming, two controller boards (a piloting board and a science board for the sensors) make the Pro-Ice quite flexible (see André et al., 2020). These can be programmed both in real time by Iridium communication and in advance by means of a script file, based on the dating of events. The dates of activation of the ISA (Ice Sensing Algorithm) for ice detection were scheduled by this script. The ISA threshold used is shown in Supplementary Table S2. In addition to this, upward winter profiles were limited to $15 \mathrm{~m}$ under ice cover as a conservative measure. As described in André et al. (2020), the schedule (time of year), ISA and altimeter results were combined by the science board to make a surfacing decision. We also developed and tested an optical ice-detection system to improve the reliability of this decision (Lagunas et al., 2018).

The time scheduling of float operation, written in the script file, evolved slightly over the period from 2016 to 2019 on the basis of experience feedback. For floats navigating before fall 2018, one profile per day was programmed until November 15th, before switching to a 28-day cycle until August 1st, then reverting to a 1-day cycle. After fall 2018, temporal resolution was increased during the winter and the spring months, to sample all events under ice. These dates were set in the script file according to ice-concentration climatology. However, especially during

${ }^{6}$ http://www.univ-brest.fr/lpo/ariane 

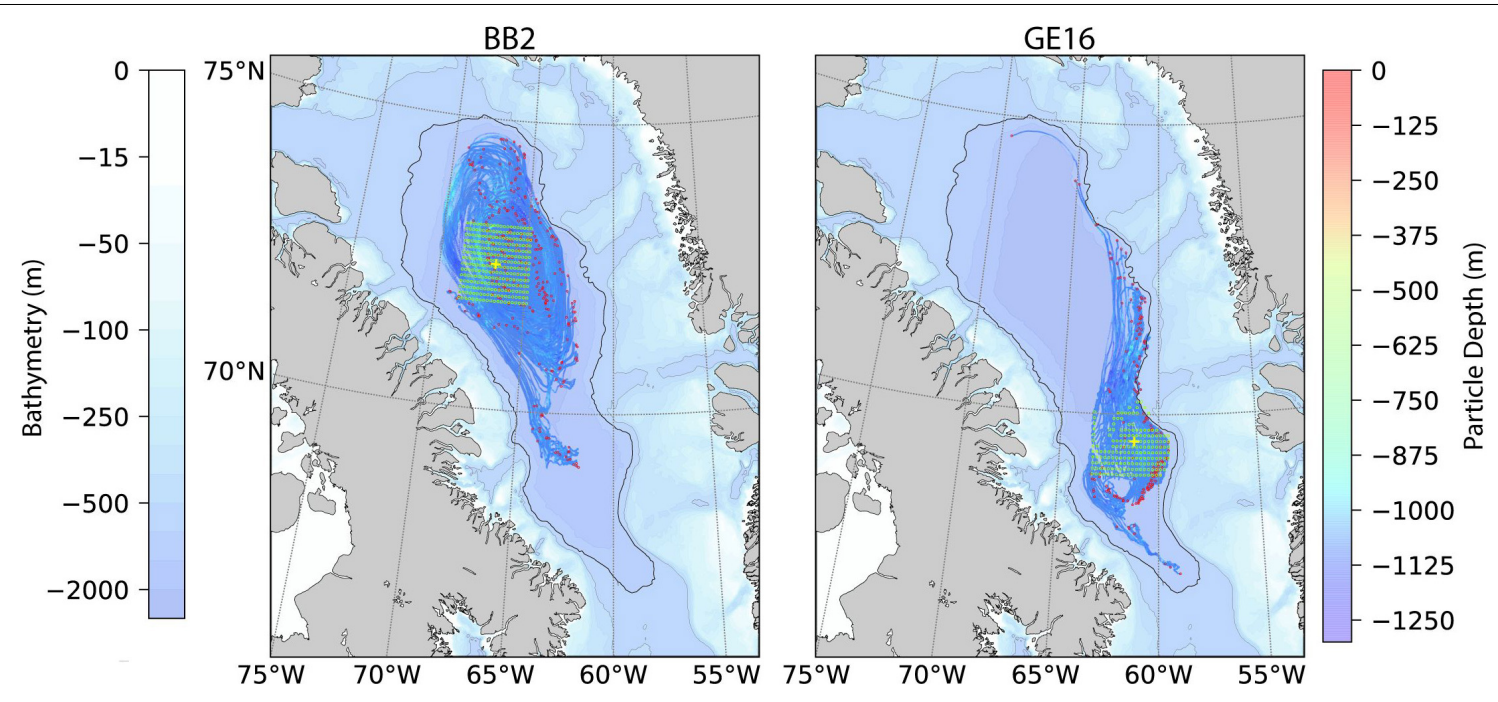

FIGURE 5 | Simulated Lagrangian particle tracking results for float deployments around BB2 (left) and GE2016 (right) zones using Ariane and GIOPS 1/4 current fields (see text). The $1000 \mathrm{~m}$ bathymetry contour is shown as a thicker black line. Particles were released at green circles; their final locations after 353 days of simulation shown as red circles. Final Pro-Ice drop zones (yellow crosses) were chosen to minimize the possibility of ejection from Baffin Bay.

fall, a daily survey of satellite ice charts (Radarsat, Sentinel1, AMSR2) and SST charts (Sea Surface Temperature) helped make decisions to switch to the winter mode earlier than midNovember when necessary.

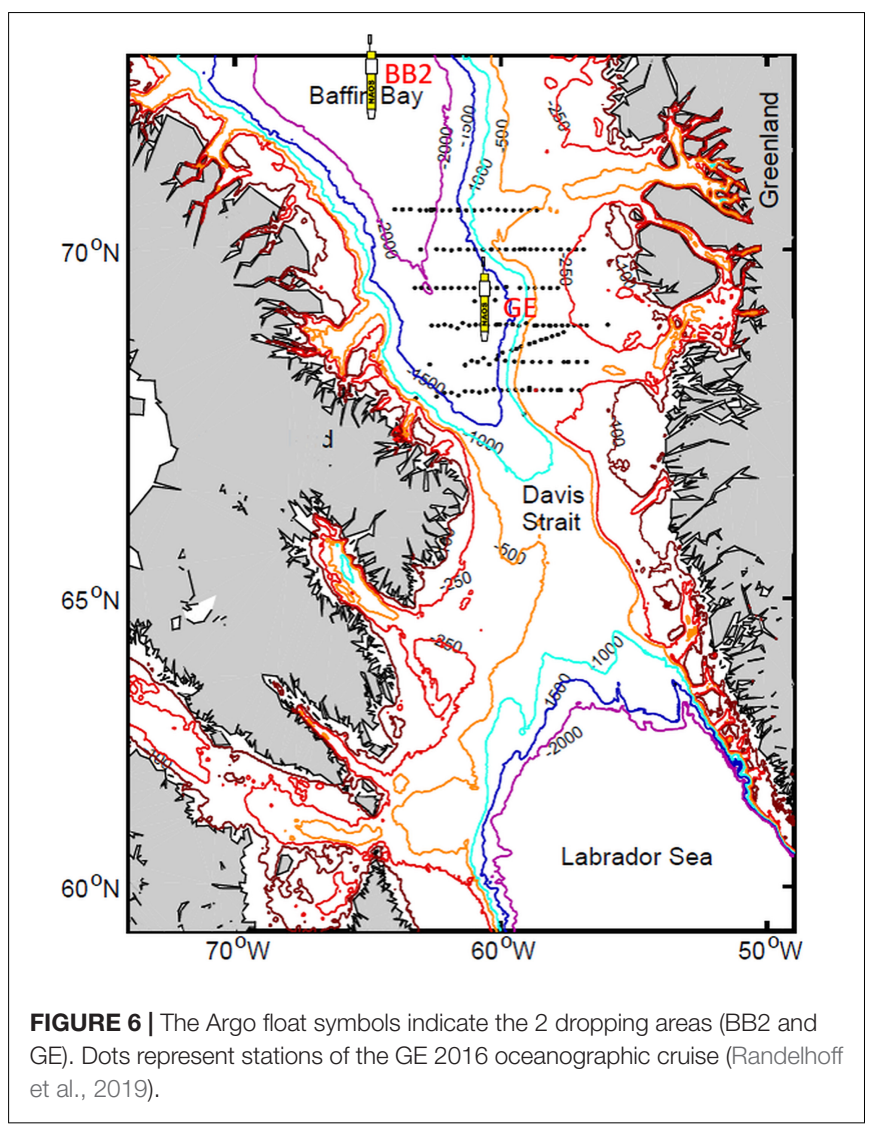

\section{Implementation and Float Performance}

Through funding from the NAOS project and the CFI, 21 Pro-Ice floats were purchased. Float deployment began in 2016 during the Green Edge cruise onboard CCGS Amundsen, with 4 Pro-Ice deployed in the GE area (see Figure 6). All four performed a hundred cycles and disappeared during the following winter. A fifth float was deployed in the Labrador Sea (André et al., 2020). During the 2017 Amundsen cruise, 4 Pro-Ice floats were deployed in the GE area and 3 in the BB2 area. Four of them were prematurely lost, two of them cycled beyond one winter (takapm012b: 388 days, 124 profiles; takapm017b: 260 days, 106 profiles), and one of them cycled beyond two winters (takapm016b: 736 days, 185 profiles). In summer 2018, two more floats deployed from the Amundsen acquired data beyond one winter (takapm020b: 452 days, 186 profiles; takapm011b: 318 days, 133 profiles). They benefited from technical improvements, notably for the management of grounding (see below) and an upgraded ISA. Two floats were deployed in the summer of 2019: one is still active, the second suffered a water leakage and may be recovered. Supplementary Table S2 presents the performance of the floats that have been deployed so far. Our experience in the Baffin Bay shows a possible life expectancy close to 200 profiles descending to $1000 \mathrm{~m}$, as described in the NAOS companion paper (André et al., 2020).

Whenever possible, floats were recovered by the C.C.G.S. Amundsen scientific crew (2 floats in summer 2018) and by the C.C.G.S. Louis St Laurent scientific crew (2 floats in fall 2019) for refitting and redeployment.

More than 1900 profiles have been collected so far by the Pro-Ice floats in the study area (Supplementary Table S2). The number of profiles acquired per float from 2016 through 2019 is shown in Figure 7, while the number of profiles per sensor package is described in Figure 8. 


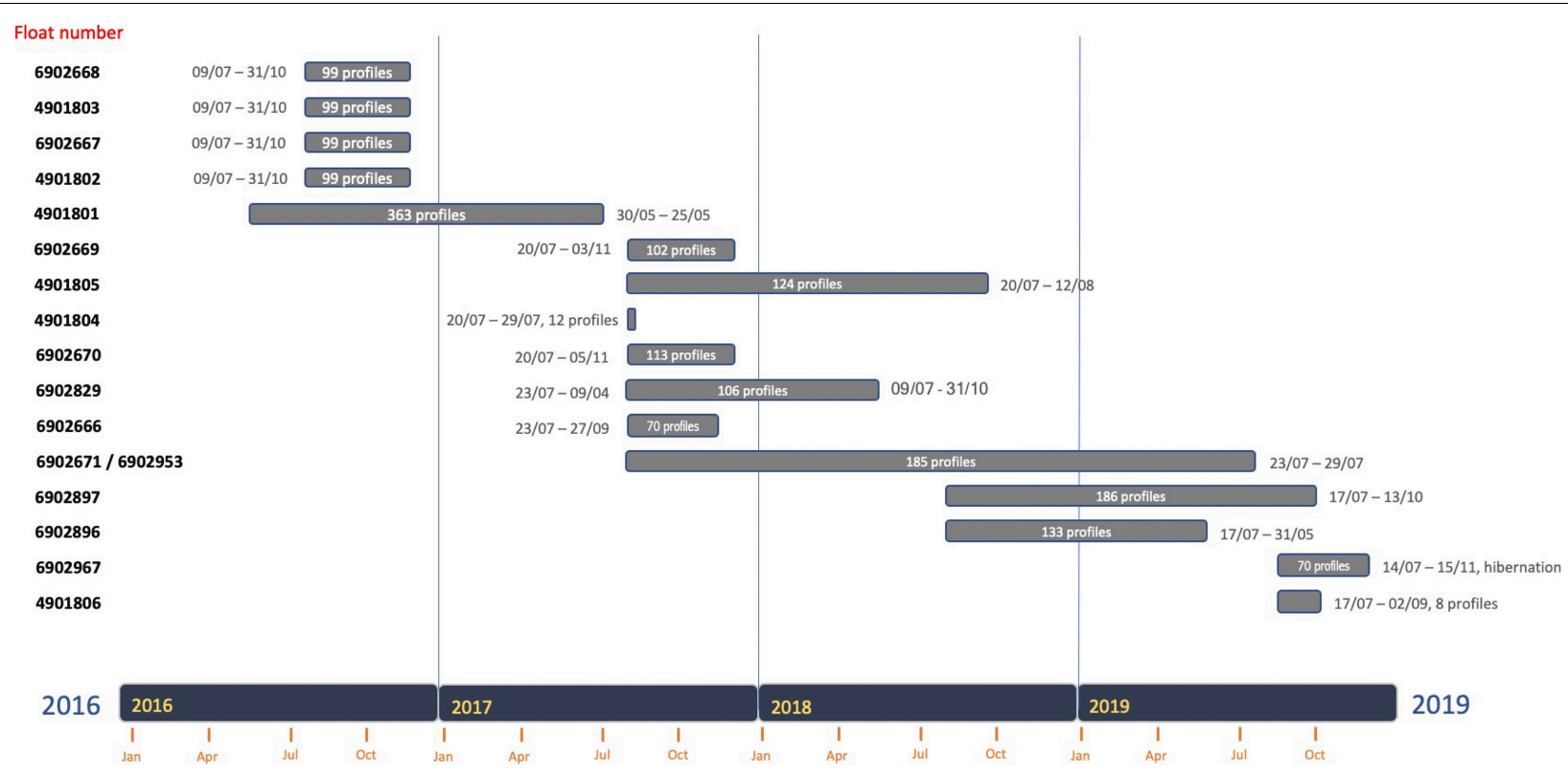

FIGURE 7 | The number of profiles per Pro-Ice float (2016-2019). All deployments took place in two main dropping zones in Baffin Bay: the BB2 ArcticNet station $\left(72^{\circ} 45^{\prime} 060 \mathrm{~N} 67^{\circ} \mathrm{OW}\right)$ at the very center of the cyclonic gyre and in southeast region $\left(69^{\circ} 30 \mathrm{~N} 61^{\circ} \mathrm{W}\right)$.

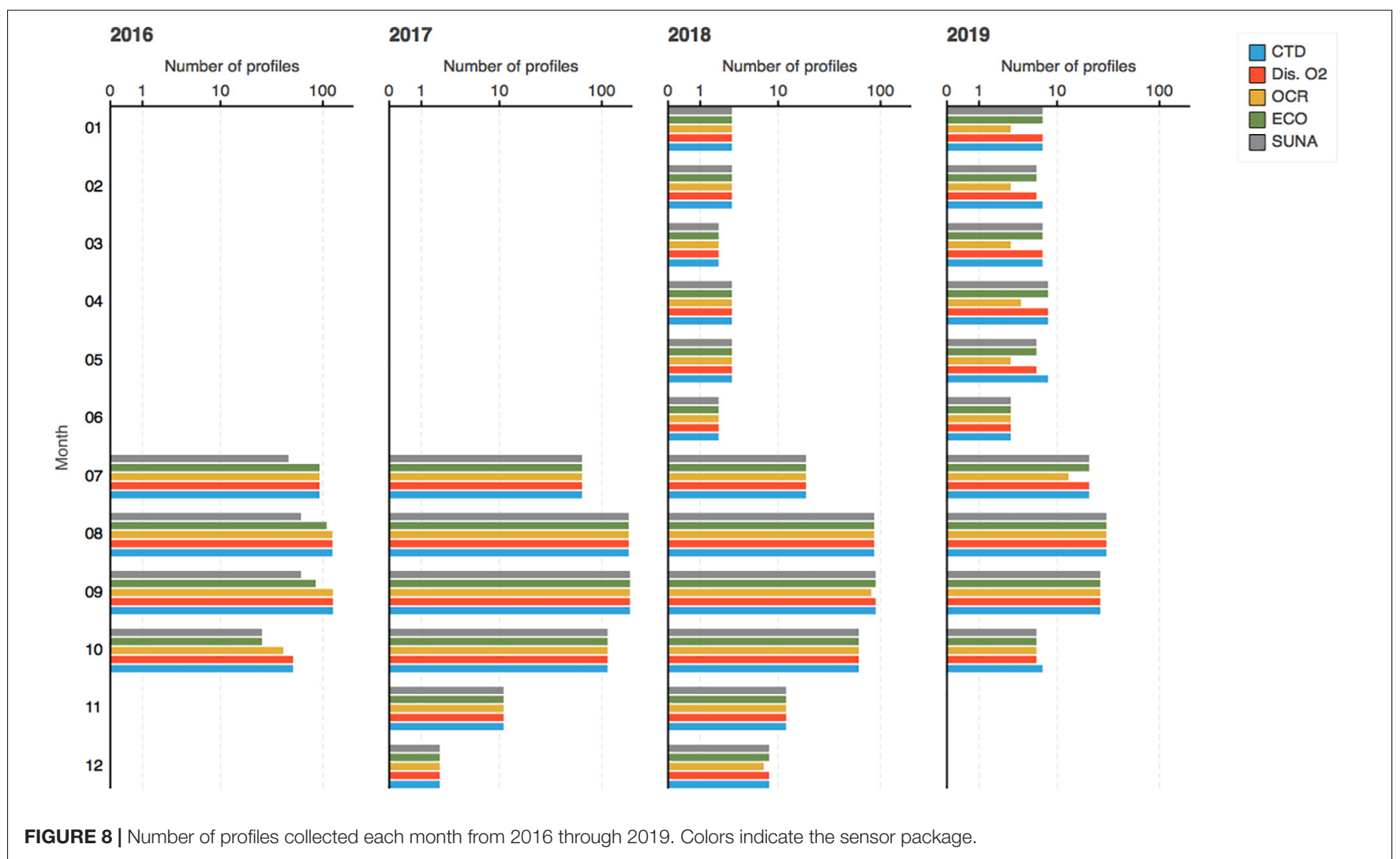

The trajectories of the floats deployed at the 2 dropping areas (BB2 and GE) are presented in Figure 9. Generally, they are consistent with the Ariane simulations shown in Figure 5. At high latitudes, partial or complete ice cover restricts access to the sea surface, denying access to satellite-based positioning and telemetry services. Trajectories of floats are therefore unknown during winter. 

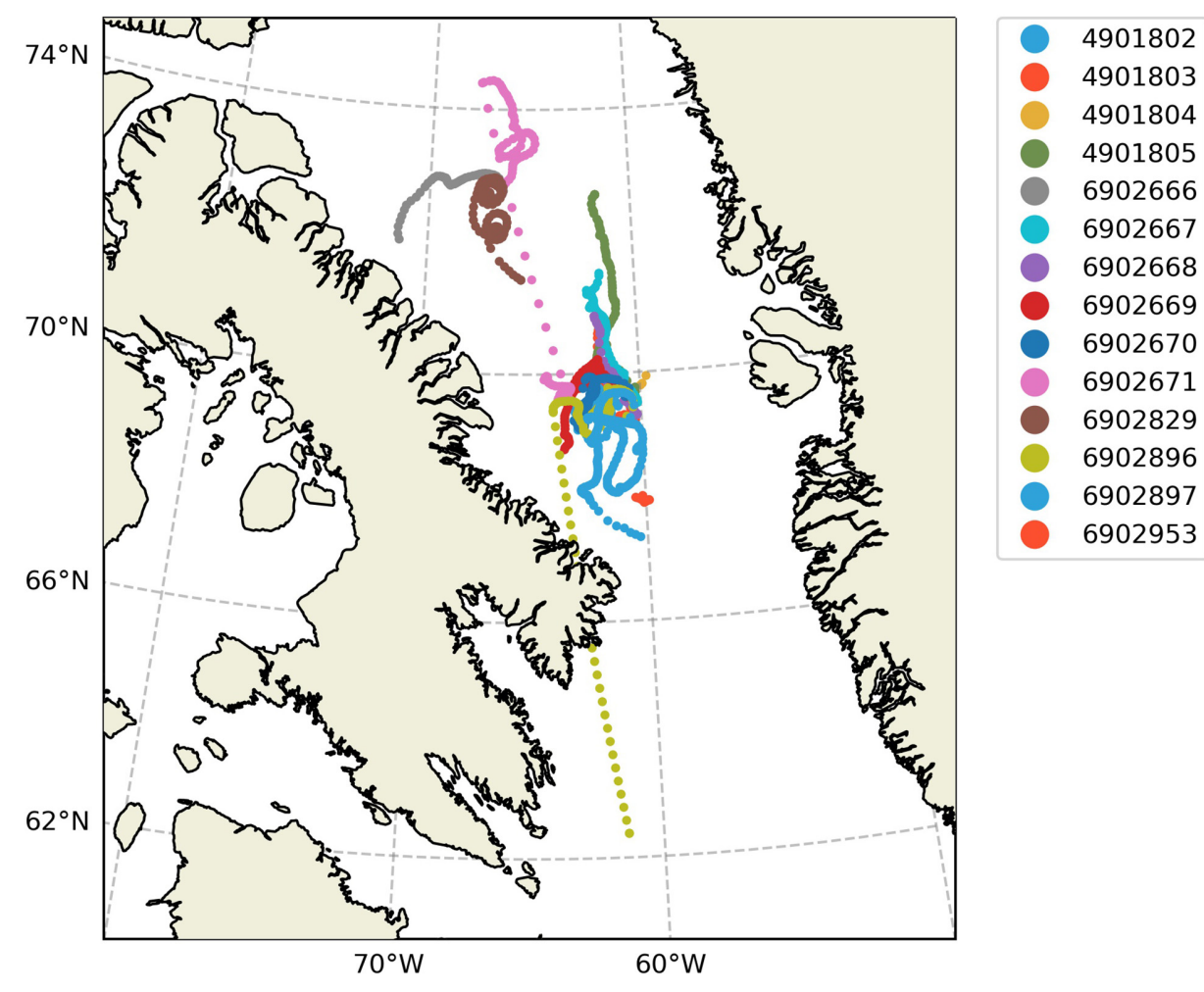

FIGURE 9 | Trajectories of floats collected from 2016-07-09 to 2019-10-12. Missing (under-ice) GPS fixes have been linearly interpolated as a visual aid.

For its emergence, a float needs to transfer oil to increase its buoyancy. In Polar regions, this amount of oil is particularly substantial to cope with seasonal desalted layers at the surface due to sea-ice melt during spring and early summer. Our experience in the Baffin Bay shows that this difficulty is particularly well managed by the Provor-type Pro-Ice floats.

The loss of Pro-Ice floats at the beginning of the campaign remains unexplained. Nevertheless, some incidents in 2017 revealed a relationship between grounding events and losses in certain circumstances. The grounding strategy therefore had to be modified, as described in André et al. (2020), and is now correctly managed thanks to the firmware implemented in mid-2018. Pro-Ice (takapm016b/WMO 6902671) was remotely upgraded in fall 2018, and was consequently given a second WMO number (6902953). It captured a two-year time-series as shown in Figure 10.

\section{Data Management and Qualification}

A $0-1000 \mathrm{~m}$ CTD-rosette cast was systematically performed right after each deployment of one or multiple floats. The CTD (Seabird SBE911+) was equipped with double temperature, conductivity, and oxygen sensors. These sensors were calibrated before and after the cruises. Seawater was also collected to evaluate and characterize calibration errors of the biogeochemical sensors (Taillandier et al., 2018; Mignot et al., 2019). Chl-a measurements were taken at 10 levels in the $100 \mathrm{~m}$ upper layer for shipboard fluorometric analyses using a Turner Designs fluorometer 10-AU and following the acidification method of
Parsons et al. (1984). In addition, samples were taken for High Performance Liquid Chromatography (HPLC) measurements of chlorophyll a concentration, performed by the SAPIGH ${ }^{7}$ national analytical service (Ras et al., 2008). Samples were taken at 10 different levels in the water column to evaluate CDOM concentration onboard using an Ultrapath spectrophotometer, as described by Bricaud et al. (2010). Sampling at 24 depths was performed for nitrate analyses using a standard colorimetric method (Grasshoff et al., 1999).

The sampling resolution of the sensors is detailed in Supplementary Table S1. Prior to deployment, data from RemA sensors (OCR504 and ECO triplet) were collected in dark conditions to evaluate their offset drift since factory calibration. A night profile was programmed as an in situ check of this offset down to $1000 \mathrm{~m}$ to cover a relatively large temperature range, which helped to determine the response of OCR to temperature (Bittig et al., 2019). Oxygen was measured by the optode with an individual factory multi-point calibration, as recommended by Bittig et al. (2018a). Oxygen data were systematically collected in air in a wet state over a 30-min period in order to evaluate the gain correction before deployment. The optodes on Pro-Ice floats are mounted on a $30-\mathrm{cm}$ stalk and twenty $\mathrm{O} 2$ in-air measurements were programmed during each surfacing of the float (Bittig and Körtzinger, 2015; Johnson et al., 2017; Bittig et al., 2018b).

Real-time quality control (RTQC) of all raw Pro-Ice data was conducted by the Coriolis data center following the standard procedures of the Argo program (Schmechtig et al., 2016).

${ }^{7}$ http://www.sapigh.obs- vlfr.fr/ 


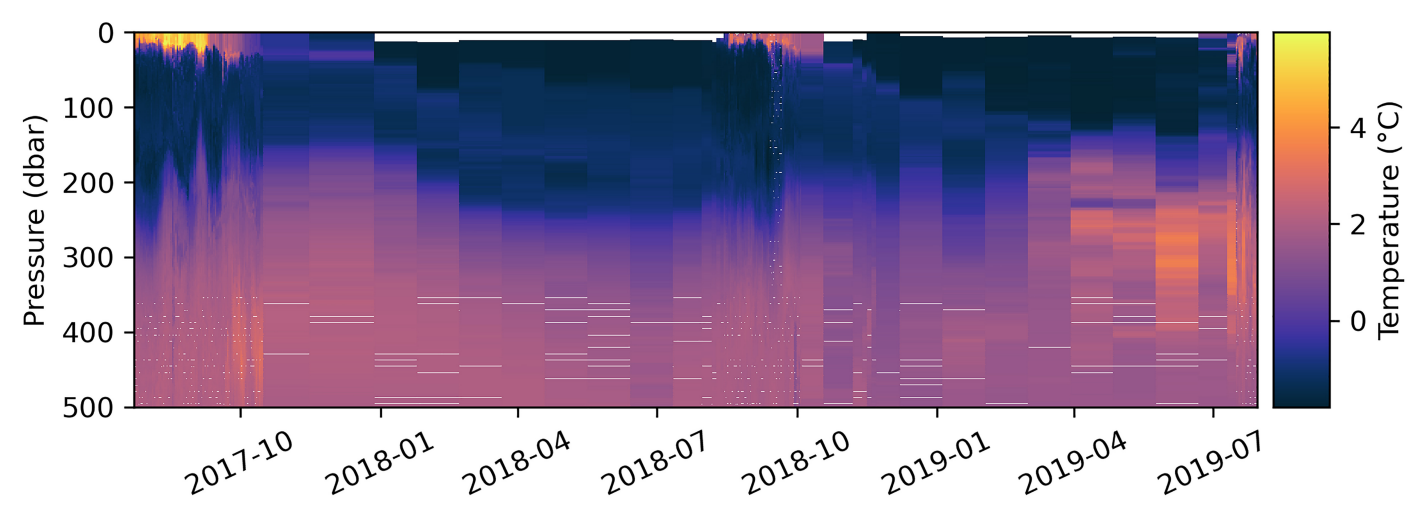

FIGURE 10 | Two-year temperature time series captured by float "takapm016b" (WMOs 6902671 and 6902953, whose change in WMO in summer 2018 was due to a firmware update).

Delayed-Mode Quality Control (DMQC) on O2, NO3, and FChla was implemented offline by Takuvik. A detailed description of DMQC procedures is given in the Supplementary Materials where Supplementary Table 3 gathers the correction coefficients.

\section{Scientific Results}

Floats have now been deployed in Baffin Bay during four successive summers (2016-19). After correcting a firmware setback that led to grounded floats during the first year, annual time series have been collected for 2 years in a row at the time of writing.

As sea ice, along with adverse winter weather, is a major impediment to the exploration and surveillance of Arctic regions, these year-round time series have presented unprecedented opportunities to study seasonal dynamics of phytoplanktonic ecosystems. So far, two studies have been conducted on phytoplankton phenology, i.e., its seasonal abundance patterns. We have investigated how vertical mixing strengthens and PAR irradiance diminishes during early fall, and how these two major constraints give rise to phytoplankton fall blooms. Randelhoff et al. (2020b) have analyzed an entire annual cycle of phytoplankton biomass, hydrography, irradiance, and sea ice cover to decipher the environmental factors controlling the spring-bloom initiation.

Given the extensive bio-optical sensor suite installed on the Pro-Ice floats, we expect a host of other future applications such as investigations into water-mass dynamics, vertical carbon export, and ocean optics. For example, Randelhoff et al. (2020a) have used the annual cycle of upper-ocean nitrate concentrations to study the vertical upward flux of nitrate in Baffin Bay, as shown in Figure 11. By considering successive vertical profiles of nitrate concentration during winter, they constrained the nitrate increase that is due to entrainment from below the mixed layer. The winter mixed layers were up to $60 \mathrm{~m}$ deep - relatively deep by Arctic standards but within the range observed in other Atlantic-influenced parts of the Arctic Ocean - and so the vertical turbulent nitrate supply in Baffin Bay was one of highest observed during the Arctic winter.

\section{Conclusions on the Use of BGC-Argo Floats in the Arctic Ocean}

The Arctic Ocean is an important component of the Earth system, especially in the current context of global warming. Yet Arctic amplification and all its related impacts, notably on biogeochemical cycles and ecosystems, remain poorly understood, mostly because they are poorly documented. Collection of data in the ice-covered Arctic Ocean still remains very limited because of difficult access to this extreme environment (Smith et al., 2019). Extending the BGC-Argo fleet to this region could significantly help fill this gap. The work achieved in Baffin Bay by NAOS has contributed to this goal.

The three main approaches for collecting long high-frequency time series in the Arctic Ocean are moorings, ice-tethered platforms (ITPs) and free-drifting profiling floats. Mooring provide Eulerian observations at a known position in delayed mode. ITPs are mostly dedicated to physical oceanography, and provide observations from given drifting ice floes (neither Eulerian nor Lagrangian) that can be located and uploaded readily in real time. As for Argo floats, up to now, only a few have been deployed in icy polar oceans, and even fewer BGCArgo floats. These offer a complement to moorings and ITPs by providing, very often, Lagrangian observations at depth in real time (ice-free) or delayed (ice-covered) mode. The expanding suite of sensors carried by BGC-Argo floats allows the study of transient processes and seasonal cycles in biogeochemical fluxes and marine ecosystems, as illustrated by the data obtained in Baffin Bay. This approach offers considerable potential, as shown by our scientific results, but some major technological challenges remain to be tackled before BGC-Argo floats can be deployed in larger numbers in ice-covered sectors of the Arctic and Antarctic Oceans. Due to recent marked increases in the size of the seasonal ice zone and the duration of the ice-free season (Arrigo and Van Dijken, 2015), further expected to grow significantly (Notz and Stroeve, 2018; Lebrun et al., 2019), the use of BGC-Argo floats for real-time operations has and will become more and more feasible in Arctic seas. On the other hand, their use under sea ice will require appropriate deployment strategies. In a recent study, Nguyen et al. (2020) showed that error in Argo's geo-positioned 

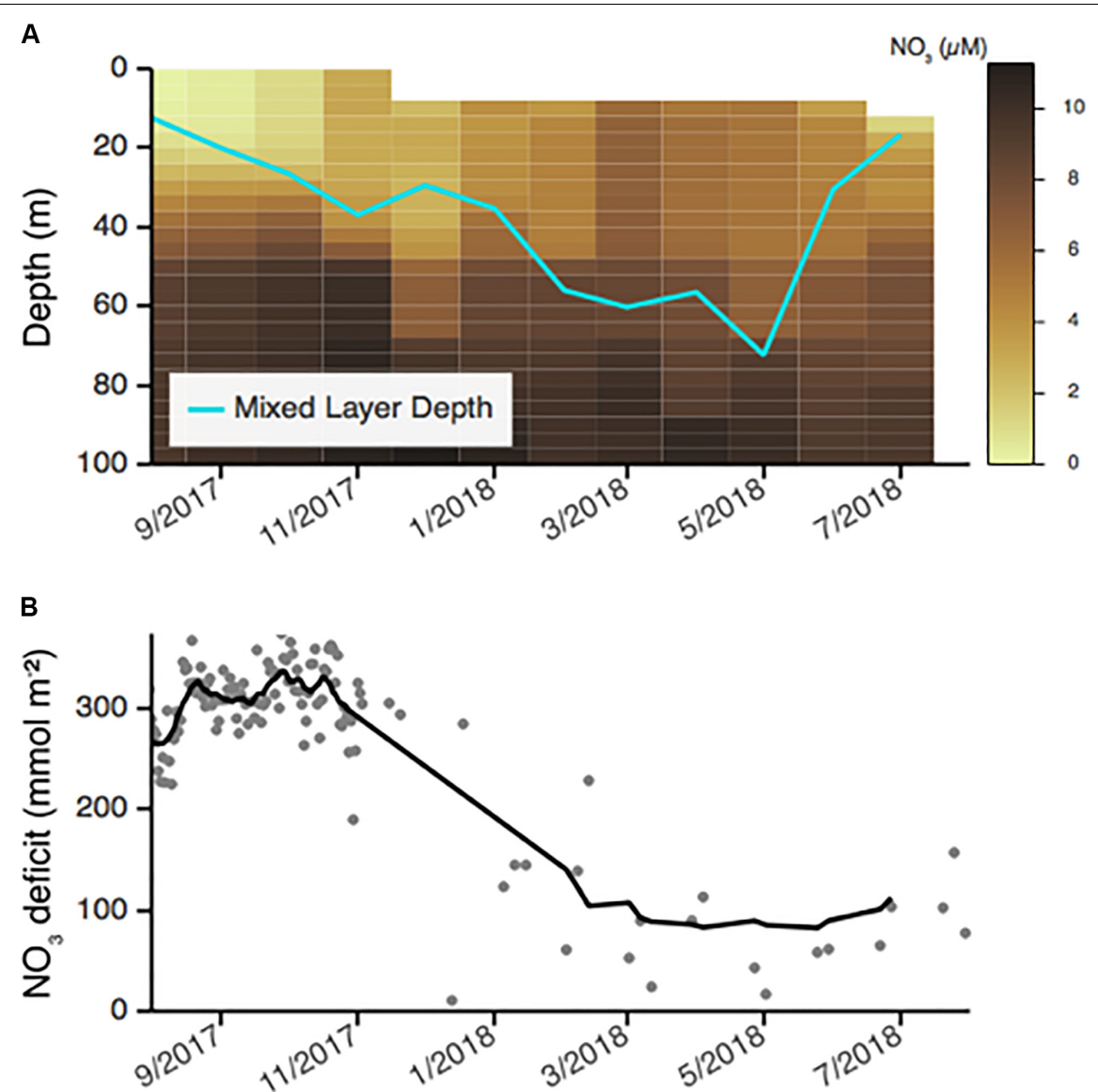

FIGURE 11 | Seasonal cycle of nitrate concentrations in Baffin Bay alongside mixed layer depth (A) and the 0-60 m vertically integrated of the nitrate deficit $\Delta\left[\mathrm{NO}_{3}^{-}\right](\mathrm{z})$ where $\Delta\left[\mathrm{NO}_{3}^{-}\right](\mathrm{z})=\left[\mathrm{NO}_{3}^{-}\right](60 \mathrm{~m})-\left[\mathrm{NO}_{3}^{-}\right](\mathrm{z})$ (B) (from Randelhoff et al., 2020a).

salinity and temperature measurements below $300 \mathrm{~m}$ due to limited surfacing opportunities in the Arctic Ocean is smaller than the uncertainty level across most of this ocean, indicating the usefulness of these measurements. At lower depths, the error is often larger, so specific strategies must be adopted. In our Baffin Bay experiments, for instance, most floats were confined within specific water masses and regions, which allowed the documentation of $1 \mathrm{D}$ processes with no need for accurate geopositioning. Similar deployments could be considered in other regions of the Arctic Ocean, in deep basins and/or slope currents (e.g., the Arctic Ocean Boundary Current along the slope of the Eurasian Basin). Finally, it should be noted that because the occurrence of leads in the icepack is high in some regions of the Arctic Ocean (Willmes and Heinemann, 2015) and may increase with the ongoing thinning of the icepack (Lindsay and Schweiger, 2015), float surfacing even in heavy ice conditions may become increasingly possible.

In recent years, the Arctic scientific community has started paying more attention to various processes taking place during the polar night under the icepack, including some phenomena related to marine ecosystems. The lifecycle and behavior of zooplankton, for instance, seem to be strongly affected by the daily cycle of twilight and even moonlight (Berge et al., 2015).
New optical sensors, such as the miniaturized Underwater Vision Profiler (Picheral et al., 2010), or much more sensitive radiometers to measure the low light levels prevailing in the water column, hold great promise for exploring unknown phenomena in the Arctic Ocean during the polar night.

To conclude, the priorities for the use of BGC-Argo floats in the Arctic Ocean should be to: (1) further test floats with ice-avoidance systems to make them more robust in cold and icy conditions, (2) add new and/or improved sensors for addressing emerging scientific issues such as polar-night biological processes, (3) develop new deployment strategies for icy conditions (e.g., boundary currents, surfacing in leads), and (4) explore possible solutions for underwater positioning based on active or passive acoustics.

\section{DEEP FLOATS WITH OXYGEN SENSORS IN THE NORTH ATLANTIC}

\section{Rationale}

The extent to which the deep interior will continue to absorb anthropogenic heat is an essential question for environmental projections, which can only be answered 
by accurate quantification of the deep thermal structure of ocean basins and their changes. The sparsity of hydrographic measurements, however, means that we currently have only relatively rough estimates of basin-averaged temperature trends, with occupations of coast-to-coast transects spaced out by 1 or 2 years at best, but usually by 5-10 years (Sloyan et al., 2019). As a result, the deep ocean (below $2000 \mathrm{~m}$ ) remains largely unknown and many questions are still open. These include, for instance, its contribution to global and regional energy and sea-level budgets (e.g., Llovel et al., 2014; Desbruyères et al., 2016; Von Schuckmann et al., 2016), its mean and time-varying large-scale circulation (Daniault et al., 2016), and the dynamical processes controlling the variability of its key water masses. To address these issues, Freeland et al. (2010), and more recently De Lavergne et al. (2016), advocated the extension of Argo measurements below $2000 \mathrm{~m}$. In response to this need, the "Deep-Arvor" float (Le Reste et al., 2016; André et al., 2020), one of the four Deep Argo float models (Roemmich et al., 2019), was developed as part of the NAOS project. The Deep-Arvor is able to measure temperature and salinity down to a depth of $4000 \mathrm{~m}$.

The deoxygenation of the ocean is a major concern in the context of climate change (Keeling et al., 2010), and the DeepArvor float is therefore equipped with an oxygen sensor to monitor oceanic oxygen content. In addition, dissolved oxygen concentration (referred to as $\mathrm{O}_{2}$ in the following) is a classic parameter in oceanography, useful for gaining insight into biogeochemical (e.g., Riser and Johnson, 2008) and physical oceanic processes (Piron et al., 2016; Racapé et al., 2019). $\mathrm{O}_{2}$ data are also important for operational oceanography that aims at monitoring and predicting the biogeochemical state of the ocean and marine ecosystems (Brasseur et al., 2009; BiogeochemicalArgo Planning Group, 2016; Le Traon et al., 2019). Note that recent studies conducted as part of the NAOS project have confirmed the central role of $\mathrm{O}_{2}$ measurements, in association with temperature and salinity measurements, to infer - through transfer functions derived from neural network techniques - the concentrations of nutrients (nitrate, phosphate and silicate) and carbonate system parameters (total alkalinity, dissolved inorganic carbon, $\mathrm{pH}$ and partial pressure of $\mathrm{CO}_{2}$ ) (Sauzède et al., 2017) (see section "Biogeochemical floats in the Mediterranean Sea").

The objectives of the NAOS Deep Argo pilot project were to demonstrate the feasibility of measuring high-quality temperature, salinity and dissolved-oxygen concentration data from Argo floats at depths greater than $2000 \mathrm{~m}$, to demonstrate the scientific value of such datasets, and to contribute to defining and initiating the extension of the Argo network toward the deep ocean. To address these objectives, it was decided to implement a Deep Argo pilot array in the subpolar gyre (SPG) of the North Atlantic Ocean, which plays a predominant role in connecting surface and deep ocean, through the formation and spread of newly ventilated intermediate and deep-water masses. In this context, several key oceanic processes can be studied on the short-term, including deep convection, deep water mass pathways and mixing. The implementation of the pilot array was made possible by the OVIDE (Lherminier et al., 2007; Mercier et al., 2015) and RREX (Petit et al., 2018) projects. These complementary observing programs provided not only deployment opportunities but also the large-scale and interannual context for data interpretation (e.g., Maze et al., 2012; Daniault et al., 2016), as well as independent datasets for sensor evaluation and data qualification.

\section{Implementation and Float Performance}

As part of NAOS, 23 Deep-Arvor floats $(0-4000 \mathrm{~m})$ equipped with oxygen sensors were purchased. Fourteen of these floats were deployed in the SPG of the North Atlantic Ocean to implement this pilot array (Figure 12) during the RREX and OVIDE/BOCATS surveys in 2015, 2016, 2017, and 2018. Two NAOS floats were deployed in the Southern Ocean as part of the CAPRICORN survey (Figure 12) to contribute to a pilot array in this region, and to evaluate sensor and Deep-Arvor float performances in ice-covered regions (see André et al., 2020). One float failed during pre-deployment tests. The 6 remaining floats will be deployed in the SPG of the North Atlantic Ocean in 2020 or 2021 (see section “Toward a Sustained Deep Argo Array”).

Except for one float (\#6901757) that completed 143 cycles and one float (\#6902811) that is still active after 91 cycles, the first batch of Deep-Arvor floats deployed until 2017 suffered from premature deaths. On average, the 10 floats performed 47 cycles while at least 120 were expected (André et al., 2020). Insight into the causes of those early failures led to improvements of both the platform and software, as detailed in André et al. (2020). Such back-and-forth between at-sea experiments and improved technology is what we expect from a pilot experiment as early failures are inherent to any technological development, especially considering the harsh environment of the deep ocean (high pressure, rough topography) and the expectations (autonomous measurements, long-life duration). This also explains why 6 NAOS Deep-Arvor floats are yet to be deployed. The 5 NAOS Deep-Arvor floats deployed since 2018 benefited from the improvements described in André et al. (2020) and are still active, as is the case of float \#6902881 (Figures 12, 13). This particular float highlights the Deep-Arvor's capability to cope with regular groundings as it sampled down to the bottom on every single cycle. With a total number of cycles ranging between 58 and 73 in early February 2020, these floats have already exceeded the mean number of cycles realized by the previous batch of floats.

\section{Data Management and Qualification}

We first investigated the behavior of the SBE41CP conductivity sensors that equip the Deep-Arvor floats. Twenty-one DeepArvor floats purchased as part of NAOS and complementary projects were considered. For each, a calibrated ship-based reference profile was acquired at float deployment. Comparisons made to the reference profiles revealed that most floats exhibited a fresh bias at depth (see Figure 13, Le Reste et al., 2016; Racapé et al., 2019). While there is certainly a pressure effect on the sensor, the question of whether this pressure effect is well corrected is also raised. We thus investigated the pressure dependency of any salinity bias by computing the salinity difference between the float and the reference profile at matching density (sigma-theta) coordinates. Salinity differences on theta levels ( $\triangle \mathrm{PSAL}$ ) were then plotted against float pressure. Moving averages of $\triangle$ PSAL over $1000 \mathrm{db}$ were computed at different 
A

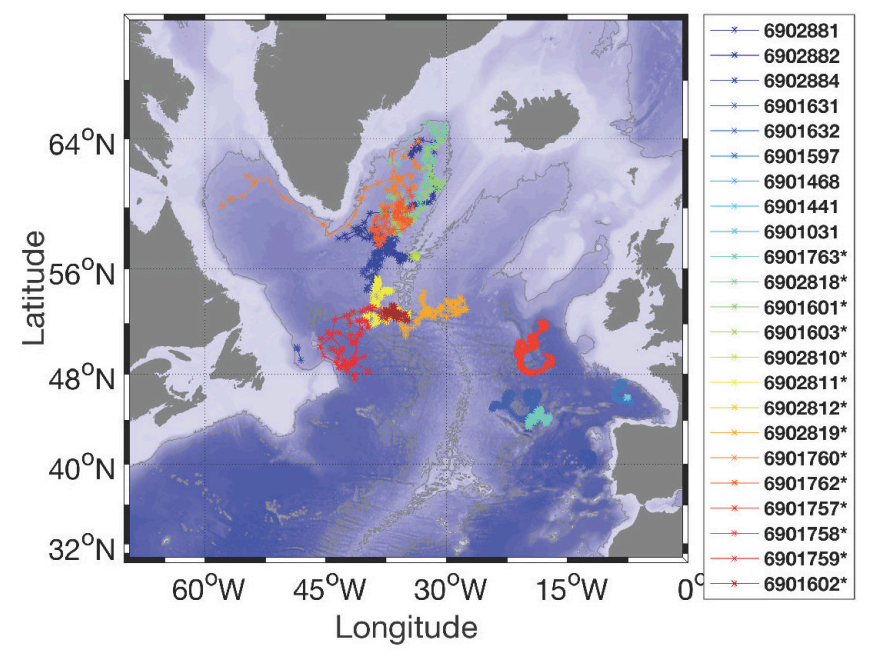

B

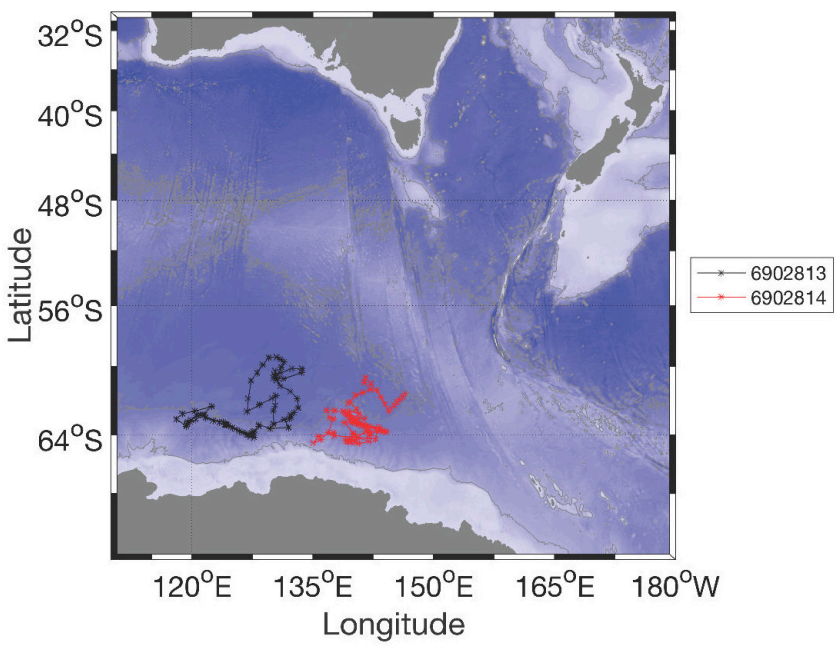

C

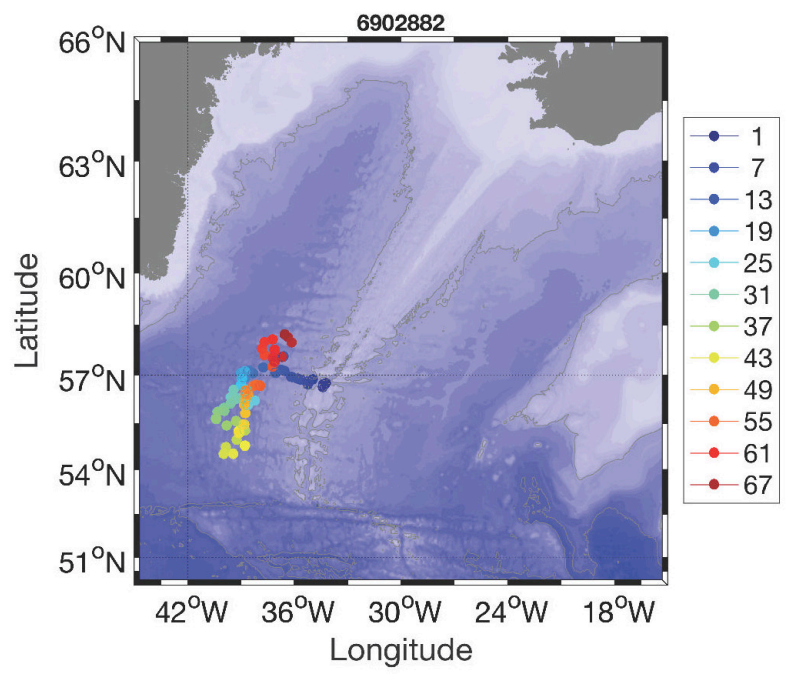

FIGURE 12 | Trajectories of (upper panel) Deep-Arvor floats deployed in the subpolar gyre of the North Atlantic Ocean, (middle panel) Deep-Arvor NAOS floats in the Southern Ocean, and (lower panel) NAOS float \#6902882. The legend provides the corresponding WMO number of the floats. In the (upper panel), NAOS floats are identified in the legend by a star besides the WMO number. In the (lower panel), the color dots represent the cycle number from dark blue (launch position) to dark red (last position), several values are indicated in the legend. 

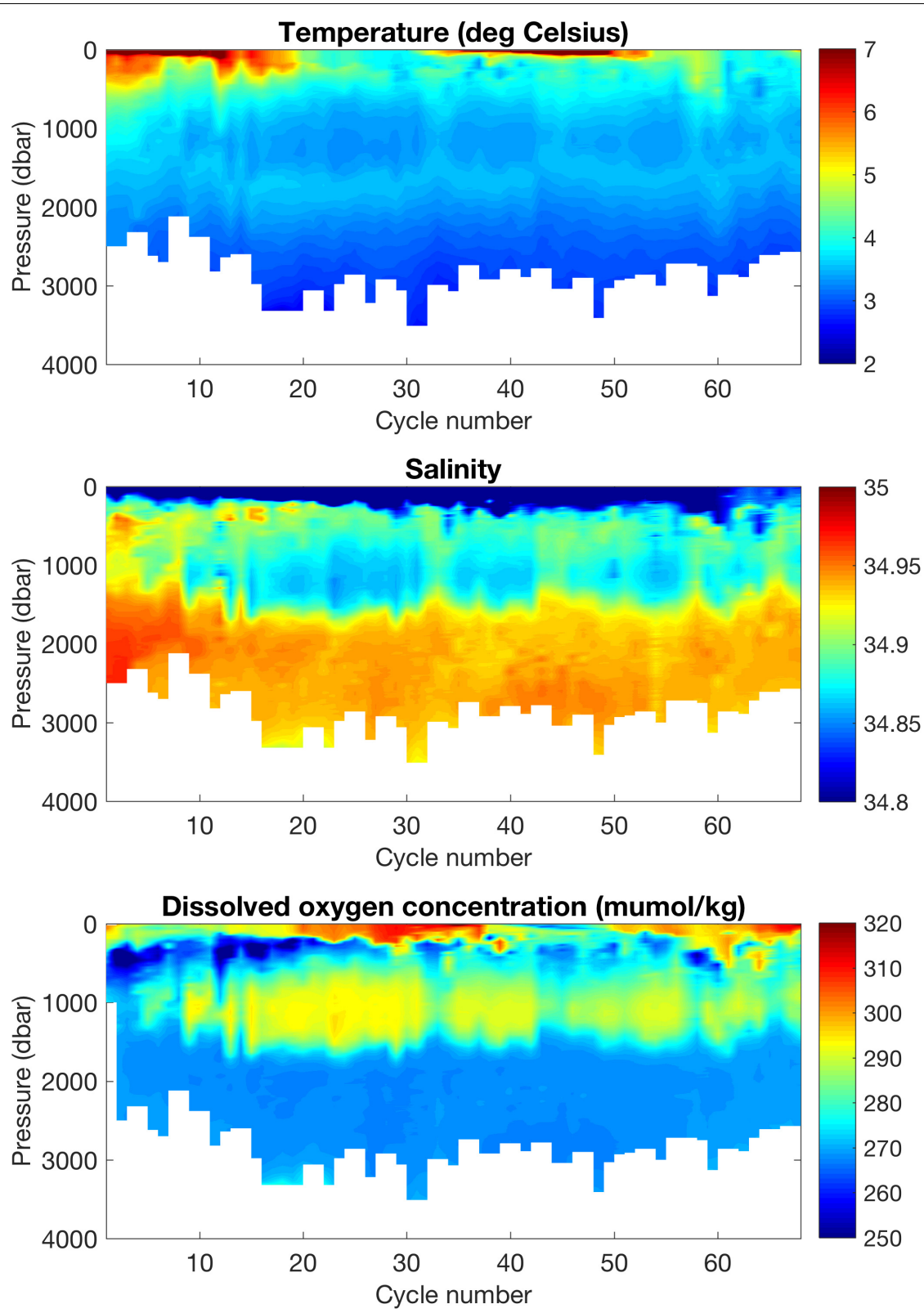

FIGURE 13 | Section of temperature (top panel; ${ }^{\circ} \mathrm{C}$ ), salinity (middle panel), and dissolved oxygen concentration (bottom panel; $\mu$ mol/kg) measured by float \#6902882 in the Irminger Sea (see Figure 12).

levels and a weighted linear fit was calculated. The fit provides the intercept at surface $(y o)$ and the slope $(r)$ (Figure 14, upper panel). Two floats (\#6902810 and 6901603) were excluded from the analysis because their first descending and ascending profiles were too shallow $(<2000 \mathrm{~m})$. In most cases, the surface offset yo was negative and generally varied between -0.004 and +0.001 . For three floats, yo was found to be less than or equal to -0.012 (Figure 14, lower panel). The slope $r$ was estimated to be negative and in the range $\left[\begin{array}{ll}-0.002 & 0\end{array}\right] / 1000$ $\mathrm{db}$ for most floats, which reveals a clear pressure response of the salinity bias. This is consistent with findings from other groups, as reported by Zilberman et al. (2019). Note that for four floats, the slope estimates were not significantly different from zero, in agreement with the findings of Le Reste et al. (2016) for float $\# 6901631$ and 6901632 . The origin of this pressure response and the way to correct it is still under discussion in the Argo community and might be due to an overestimation of the conductivity pressure effect correction coefficient (CPcor) provided by Seabird (Zilberman et al., 2019). Two floats experienced permanent or temporary jumps toward larger fresh bias (\#6901631 and 6901757) and two floats experienced a linear salty drift (\#6901758 and 6902818). These issues are a current concern among the Argo community and are not specific to the Deep-Arvor. 


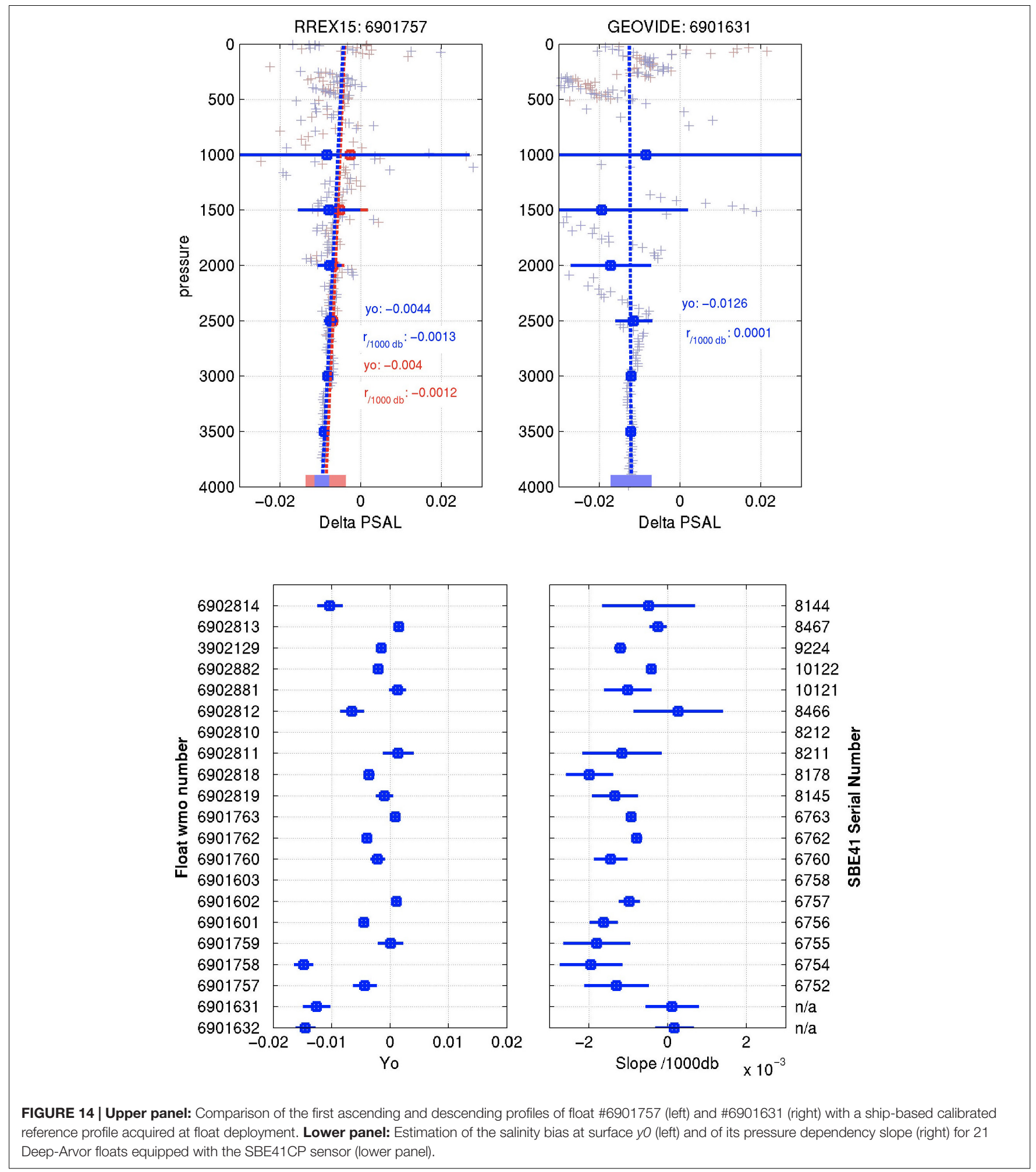

One major contribution of the NAOS project is its implementation of the procedure for managing oxygen data in the Argo data stream. This activity contributed to the BGCArgo component (Biogeochemical-Argo Planning Group, 2016), and was conducted in close collaboration with European and international partners (Bittig et al., 2019). Through NAOS therefore, a manual describing oxygen data management processing was written and kept up-to-date (Thierry et al., 2018a), and in addition, the Real-Time and Delayed-Mode Quality Control procedure for oxygen data acquired by Argo floats 
was established (Schmechtig et al., 2016; Thierry et al., 2018b). A software (LOCODOX) was developed to correct oxygen data acquired by Aanderaa optode sensors equipping Argo floats from any sensor bias (due to drift during storage) and in situ drift (Thierry et al., 2020). Correction is made either by comparison with in situ reference data following Takeshita et al. (2013) or with in-air measurements following Bittig and Körtzinger (2015) or Johnson K. S. et al. (2015). According to a comparison with ship-based high-quality reference profiles, additional pressure correction was required on some floats (Gallian and Thierry, 2018; Racapé et al., 2019). While a simple pressure-correction model helps remove this pressure-dependent bias, its origin still needs to be determined.

\section{Scientific Results}

The Meridional Overturning Circulation (MOC) is a key component of the Earth's climate as it contributes to the redistribution of heat, salt, oxygen and carbon within the world ocean. In the North Atlantic Ocean, the cooling and densification of the warm and salty water masses of the upper limb of the MOC and the resulting convection lead to the formation of oxygen-rich intermediate and deep-water masses, such as Labrador Sea Water (LSW) and Iceland Scotland Overflow Water (ISOW), which feed the lower limb of the MOC. LSW is a lowsalinity intermediate water formed by deep convection in the Labrador and Irminger Sea. ISOW is a dense water mass of the North Atlantic Ocean originating from the Nordic Seas and characterized by salinity higher than 34.94 and density greater than $27.8 \mathrm{~kg} / \mathrm{m}^{3}$. Data from NAOS floats in the North Atlantic Ocean were used to investigate circulation of the deep-water masses belonging to the lower limb of the MOC (Daniault et al., 2016) as well as deep convection processes and oxygen supply to the deep layers.

Five of the NAOS Deep-Arvor floats were deployed in the Charlie-Gibbs Fracture Zone (CGFZ), a gap in the Mid-Atlantic Ridge known to channel ISOW from the Iceland Basin to the Irminger Sea. The floats drifted in the core of ISOW at $2750 \mathrm{~m}$. Based on the mean circulation scheme of Daniault et al. (2016), we expected that all the floats would veer northward downstream of the CGFZ and flow cyclonically in the Irminger Sea. However, Racapé et al. (2019) showed that none of the floats reached the Irminger Sea and one float even revealed a new direct route from ISOW toward the subtropical gyre without looping in the Irminger Sea. Oxygen data acquired by the floats showed that the ISOW layer was mainly composed of highly oxygenated ISOW and less oxygenated North East Atlantic Deep Water (NEADW), a complex water mass from the East Atlantic. Racapé et al. (2019) also showed that mixing between ISOW and NEADW was favored by northward intrusions of the North Atlantic Current. The ISOW-NEADW signal flowing westward from the CGFZ toward the Deep Western Boundary Current (DWBC) was progressively diluted by Labrador Sea Water and Denmark Strait Overflow Water (DSOW). These results highlight how Deep Argo data can improve our understanding of deep circulation and in particular, how oxygen data are essential for a better grasp and characterization of the mixing and spreading of deep water masses.
Owing to the core Argo floats deployed in the SPG of the North Atlantic Ocean, including NAOS floats (see section "Contribution to the Core Argo Program"), we investigated deep convection processes in the Irminger Sea and Labrador Sea. We described for the first time the different phases of the mixed layer deepening down to $1000 \mathrm{~m}$ in the Irminger Sea during winter 2011-2012 (Piron et al., 2016). We showed that deep convection in the Irminger Sea exceptionally reached $1400 \mathrm{~m}$ during winter 2014-2015 (Piron et al., 2017), then persisted for four consecutive winters (2015-2018) (Zunino et al., 2020). These studies revealed the importance of enhanced Argo sampling to investigate deep convection processes and of oxygen data to testify to the local formation of the deep mixed layers. We showed that Greenland Tip Jets - intense narrow and sporadic winds east of Cape Farewell - were of primary importance for the development of deep convection in the Irminger Sea in the winter of 2011-2012 (Piron et al., 2016), and that exceptional heat loss to the atmosphere (up to $50 \%$ higher than the climatological mean) drove the very deep convection observed in winter 2014-2015 (Piron et al., 2017). On the other hand, deep convection in winter 2016-2018 was not due to anomalous atmospheric forcing but to favorable preconditioning of the water column under average forcing conditions (Zunino et al., 2020). On the basis of Argo- $\mathrm{O}_{2}$ data, Wolf et al. (2018) suggested that the Labrador Sea is a net sink for atmospheric oxygen. They showed that in the Labrador Sea, mixed layers deeper than $800 \mathrm{~m}$ are undersaturated at $-6.1 \%$ to $-7.6 \%$ at the end of convection and that lateral processes act to lower the oxygen inventory of the central Labrador Sea.

\section{Toward a Sustained Deep Argo Array}

Results and experiences gained from the NAOS project were shared among the international scientific community involved in Deep Argo activities (Zilberman and Maze, 2015; Zilberman et al., 2019). Results from the NAOS project and from complementary regional Deep Argo pilot experiments conducted in the South Pacific and South Indian Oceans, using Deep Argo floats with $6000 \mathrm{~m}$ (Deep SOLO, Deep SOLO-MRV, and Deep APEX) or $4000 \mathrm{~m}$ (Deep-Arvor and Deep NINJA) capability, are summarized in Roemmich et al. (2019). These pilot experiments demonstrated the feasibility of a Deep Argo array and contributed to defining the new Argo program as an array that is global in extent, full depth and multi-disciplinary (Roemmich et al., 2019). The objective of the Deep component of the Argo array is to maintain about 1250 active Deep Argo floats at $5^{\circ} \times 5^{\circ}$ spacing (Johnson G. C. et al., 2015) and cycling every 10 days in order to also contribute to the core Argo program. The Deep Argo array will be a mixture of 4000 and $6000 \mathrm{~m}$ floats to monitor, in a cost-effective manner, both the deep layer (2000-4000 m) and the abyssal layer $(>4000 \mathrm{~m})$ that represent about 39 and $12 \%$ of the total ocean volume, respectively (De Lavergne et al., 2016; Le Reste et al., 2016). The proportion of 4000 and $6000 \mathrm{~m}$ floats in each basin will depend on the bottom topography but also on the spatial pattern and temporal variability of the signal of interest (heat content and large-scale circulation), which remain to be determined. In expanding deep-ocean data coverage, the Deep Argo array will improve our ability to monitor regional to global variability in ocean heat and freshwater contents and 
associated sea-level rise, our scientific understanding of deepocean dynamics and global overturning circulation, as well as short- and long-term climate forecasting.

To make the transition from regional pilot phase to global implementation, it is still necessary to assess the accuracy and long-term stability of CTD measurements, to define real-time and delayed-mode quality control procedures, and to deploy and maintain a sufficient number of active floats to reach the target of 1250 active floats.

To assess the accuracy and long-term stability of CTD measurements, we developed, as part of the NAOS project, the 3-headed Deep-Arvor, equipped with the standard SBE41CP sensor, and two additional CTDs: the RBRconcerto and the SBE61CP (André et al., 2020). This profiling float was designed as an intercomparison platform to evaluate the three CTDs at sea. Long-term deployment of the two 3-headed Deep-Arvor floats funded by the NAOS and European Euro-Argo RISE projects are planned for 2020. The quality control procedure of Deep Argo data will also be addressed as part of the Euro-Argo-RISE project.

The transition from regional pilot array to global array should conform to the following principles (Roemmich et al., 2019): maintenance and expansion of the spatial domain of the existing regional pilot array; initiation of new regional arrays, starting with areas where the deep layers are believed to undergo substantial decadal changes, seasonal cycles, or other variability, and that are close to deep-water and bottom-water formation sites. The European strategy is in line with these principles and specifies that: (1) deployments will firstly be focused in the North Atlantic Ocean and Southern Ocean where deep-water formation drives substantial deep property changes, and (2) deployment will subsequently follow deep-water mass pathways in the Atlantic and the Southern Ocean. The longterm European contribution to the Deep Argo array will be about $20 \%$ of the international target which, based on the strawplan of Johnson G. C. et al. (2015), would correspond to about 240 active floats. Considering a lifetime of 150 cycles (without $\mathrm{O}_{2}$ sensor; 130 cycles with $\mathrm{O}_{2}$ ) and a 10-day cycle, the float lifetime is about 4 years. The European target is thus to deploy 50 floats per year.
The French contribution to the Deep Argo array will follow the European strategy (Euro-Argo ERIC, 2017) and will make up $30 \%$ of the European contribution, that is 15 floats per year. On this basis, we first plan to maintain the Deep Argo array in the SPG of the North Atlantic Ocean. According to the Deep Argo sampling strategy, the SPG area $\left(10^{\circ} \mathrm{W}-60^{\circ} \mathrm{W}\right.$, $45^{\circ} \mathrm{N}-65^{\circ} \mathrm{N}$ ) would require a permanent fleet of about 40 deep floats. As a point of comparison, the core Argo array in the SPG currently comprises 150 floats. Based on topographic and key current features, the SPG domain can be grossly divided into five subzones for coordinating repeated deployments and favoring a homogenous coverage of the domain: the Labrador Sea, the Irminger Sea, the Iceland Basin, the Newfoundland Basin, and the Iberian Plain. The random distribution of 40 floats in water depth $>2000 \mathrm{~m}$ in the SPG is shown in Figure 15 (8 floats per zone). The current Deep Argo database in the SPG comprises about 1200 profiles (Figure 12), mainly fed by NAOS DeepArvor floats (14). Seven additional Deep-Arvor floats, either prototypes or provided by Argo-France, also contributed to the Deep Argo pilot array. Amongst the 21 deep floats deployed in the SPG since 2012, five are currently active. Owing to deployment opportunities provided by the OSNAP (Lozier et al., 2019) and OVIDE (Mercier et al., 2015) projects, we will launch the first phase of the array-implementation plan by providing about 40 deep floats (remaining NAOS floats to be deployed and Argo-France funding) and coordinating their deployments within each of the 5 target zones during 2020-2021. As illustrated on Figure 15, the deployment directive for this first phase of implementation will be to deploy 4 floats in the deepest (central) part of each target zone and another 4 floats in key dynamical locations such as boundary currents or fracture zones.

We also plan to expand the North Atlantic Deep Argo array southward (in the subtropical gyre and tropical area of the Atlantic Ocean) in the coming years, and to contribute to the Deep Argo array in the Southern Ocean whose deep and abyssal layers are warming at the highest rates (Bindoff et al., 2019). The ocean bottom being deeper than $4000 \mathrm{~m}$ (the Deep-Arvor float capability) in the latter region, part of the fleet there could be switched to $6000 \mathrm{~m}$ floats in the near future.

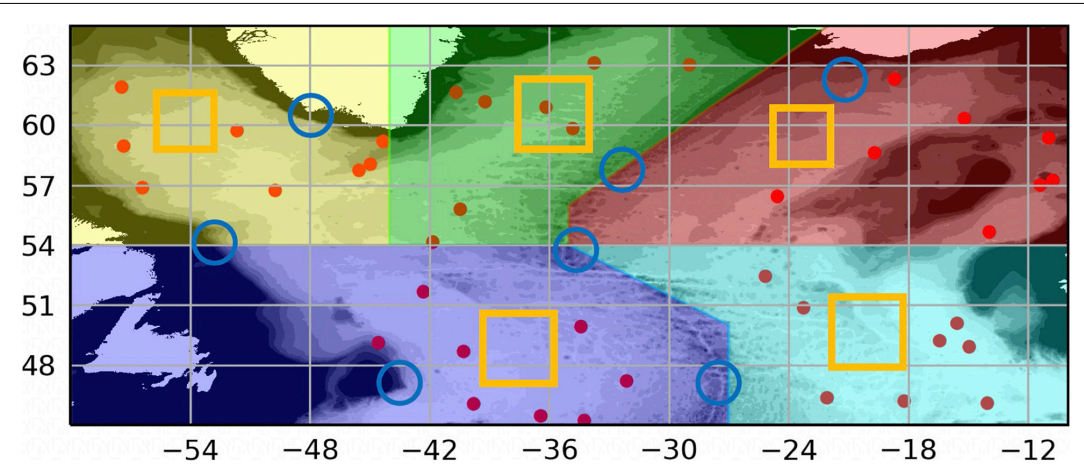

FIGURE 15 | Straw-plan of a nominal $5^{\circ} \times 5^{\circ}$ Deep Argo array in the SPG. Five target zones (color polygons containing 8 floats) are roughly identified to define a long-term and collaborative deployment strategy. Yellow boxes and blue circles indicate suggested deployment locations to ensure monitoring of both quiescent deep basins and energetic boundary currents, respectively. LS, IS, IRO, NFB, and IP stands for Labrador Sea, Irminger Sea, Iceland-Rockall area, New Foundland Basin, and Iberian Plain, respectively. 


\section{PERSPECTIVES AND CONCLUSION}

Thanks to NAOS, the French contribution to Argo has been significantly improved via the deployment of more than 100 NAOS standard Argo profiling floats. In parallel, the three scientific experiments undertaken by NAOS have allowed the collection of unique observations that have reaped many new results and findings, in particular, on biogeochemical cycles in the Mediterranean Sea and the Arctic Ocean, and deep-ocean variability in the North Atlantic.

NAOS has successfully developed and tested the technology required to launch a new phase of Argo in France. Outcomes and lessons learned from NAOS pilot experiments, as outlined in the previous sections, will guide the development of this new phase.

Following Euro-Argo and Argo international strategies to develop a fully global, top-to-bottom, dynamically complete, and multidisciplinary Argo program (Euro-Argo ERIC, 2017; Roemmich et al., 2019; Claustre et al., 2020), the Argo-France objective for the next decade is to sustain a contribution to the Argo core mission and the Deep Argo and BGCArgo extensions. The plan is to deploy $70-80$ floats/year, with 30 T\&S floats, 15 deep floats, 15 floats with oxygen sensors and 15 BGC floats measuring the six core BGC-Argo variables. France will continue its leadership in Argo datamanagement activities with the operation of one of the two GDACs as well as the French/European DAC. In addition, France will play a leading role in BGC-Argo data management and scientific validation.

Argo-France will continue to work in areas of strong interest for the French research community: North Atlantic, Mediterranean Sea, tropical regions (Atlantic in synergy with the PIRATA array and Pacific in synergy with the TPOS2020 array), Arctic Ocean and Southern Ocean. These contributions will be aligned with European and international strategies to ensure that they build toward a truly global and optimized array both for the core Argo program and its Deep and BGC extensions.

Integration with satellite observations, other in situ observing systems and models will remain a strong focus of Argo-France (e.g., Gasparin et al., 2019; Le Traon et al., 2019). The integration of BGC-Argo observations with ocean-color satellite data in biogeochemical models (e.g., Cossarini et al., 2019) opens up exciting prospects of outstanding advances in biogeochemistry research and operational applications, akin to what has been achieved for physics through core Argo and satellite altimetry data (e.g., Le Traon, 2013).

As far as float technology is concerned, two main developments are planned for the coming years: (1) a Deep-Arvor $6000 \mathrm{~m}$ float that will sample deeper layers and offer a carrying capacity for additional sensors (e.g., oxygen, pH), and (2) a new generation of French BGCArgo floats (BGC-Argo "second generation") adding imaging and active-acoustics capabilities. Deep-Arvor $6000 \mathrm{~m}$ floats will be combined with the NAOS Deep-Arvor $4000 \mathrm{~m}$ floats to cost-effectively sample deep ( $>2000$ dbar $)$ and abyssal ( $>4000$ dbar) layers. The second generation of BGC floats will allow exploration of the mesopelagic zone $(100-1000 \mathrm{~m})$ to delve into its biological/fishery dimension (protein resources in this area are thought to be underestimated by at least one order of magnitude) and also its key role in $\mathrm{CO}_{2}$ sequestration as the main seat of its remineralization.

NAOS has been instrumental in developing Argo-France activities over the past 10 years. Perspectives for the next decade of Argo and Argo-France are just as exciting and will lead to many new advances in our understanding of the ocean physics, biogeochemistry and marine ecosystems.

\section{DATA AVAILABILITY STATEMENT}

The datasets presented in this study can be found in online repositories. The names of the repository/repositories and accession number(s) can be found below: http://www. argodatamgt.org/Access-to-data/Access-via-FTP-or-HTTPS-onGDAC.

\section{AUTHOR CONTRIBUTIONS}

P-YL and FD'O supervised the scientific activities described in this manuscript. P-YL wrote the abstract and the introduction, led the writing of the conclusion, contributed to the writing of section "Contribution to the Core Argo Program", and reviewed the whole manuscript content. SP with the help of NP led the writing of section "Contribution to the Core Argo Program". FD'O led the writing of section "Biogeochemical Floats in the Mediterranean Sea" and reviewed the whole manuscript content. VTa, CP, AP, EL, TW, and FD'O handled the logistics of the deployments in the Mediterranean Sea. VTa, LP, TW, and FD'O processed the Mediterranean Sea data. CM and $\mathrm{MB}$ led the writing of section "Biogeochemical Floats in the Arctic Ocean". EL and CP worked on the technological development of Pro-Ice with the help of CM and J-LL who together managed the fleet logistics. MB, AR, and LL carried out the data analysis as well as XX who worked also on the Pro-Ice data qualification. ER performed the simulation of the Pro-Ice trajectories. VTh led the writing of section "Deep Floats With Oxygen Sensors in the North Atlantic" with the help of DD and CC. CC worked on the Deep-Arvor data qualification. CS handled the BGC data management with the contribution of AP and HC. All authors read and approved the submitted version.

\section{FUNDING}

The NAOS project is the result of a strong partnership between Ifremer (coordinator), UPMC (co-coordinator), CNRS (INSU), UBO/IUEM (PRES UEB), SHOM and two private companies: CLS for satellite-telecommunications aspects and the SME nke instrumentation which is in charge of industrializing and marketing the French Argo floats. The NAOS project received support from the French Ministry of Research under the 
"Investissements d'avenir" program. This support, managed by the National Research Agency (French ANR), is referred to as ANR-10-EQPX-40. Mediterranean activity was partially cofunded by the remOcean (European Research Council, grant 246777) and BioArgo (CNES-TOSCA) projects. The Canadian Foundation for Innovations (CFI) John R. Evans Leaders Fund \#30124 covered the acquisition of 9 Pro-Ice floats. The Canadian Excellence Research Chair in Remote Sensing of Canada's New Arctic Frontier covered the wages of some research assistants. The European Commission Horizon 2020 grant \#727890 to the Integrated Arctic Observation System INTAROS covered travel expenses related to the deployment of the Pro-Ice floats and coordination efforts. Regarding Pro-Ice deployments, support was given by NSERC for ship-time:

- 2016: NSERC Ship-Time program (\# RGPST-486341-2016).

- 2017: NSERC Ship-Time program (\# RGPST-501172-2017).

- 2018: Ship-time was supported by the Sentinel North program of Université Laval, made possible, in part, thanks to funding from the Canada First Research Excellence Fund.

- 2019: NSERC Ship-Time program (\# RGPST-531424-2019).

- As well as help from the Green Edge project (http: //www.obsvlfr.fr/proof/php/GREENEDGE/greenedge_ autonomous.php).

Takuvik's laser ice-detection project was financially supported by the French National Center for Scientific Research (CNRS) through their program for innovation and technology development Defi Instrumentation aux limites (2015). The French cruises involved in the NAOS Deep-Arvor float deployment were supported by the French Oceanographic Fleet (TGIR FOF). This work was also supported by the AtlantOS project funded by the European Union's Horizon 2020 research and innovation program under Agreement \#633211.

\section{ACKNOWLEDGMENTS}

V. Le Saout ran the NAOS project office right from the start of the project. Her help has been invaluable to the project's success. NAOS float technology developments were led by S. Le Reste and $\mathrm{X}$. André with extreme professionalism. We thank N. Lebreton from the Coriolis deployment team for her assistance during the acceptance tests and deployments of profiling floats. We thank colleagues from LOPS/TOIS and ship crews of the RV Thalassa, Atalante, Pourquoi Pas?, Sarmineto del Gamboa and investigators

\section{REFERENCES}

André, X., Le Traon, P. Y., Le Reste, S., Dutreuil, V., Leymarie, E., Malardé, D., et al. (2020). Preparing the new phase of Argo: technological developments on profiling floats in the NAOS project. Front. Mar. Sci.

Arrigo, K. R., and Van Dijken, G. L. (2015). Continued increases in Arctic Ocean primary production. Prog. Oceanogr. 136, 60-70. doi: 10.1016/j.pocean.2015. 05.002

Artana, C., Lellouche, J.-M., Sennéchael, N., and Provost, C. (2018). The openocean side of the Malvinas Current in Argo float data and 25 years of reanalyses involved in the NAOS Deep-Arvor float deployment. We thank crews and captains of the RV Tethys-II, Le Suroit and Pourquoi Pas? for at sea activity in the Mediterranean related to BGC-floats. Many thanks also go to the projects MERMEX (Chantier Med INSU), BOUSSOLE (CNES-TOSCA), Argo-Italy and MOOSE, which provided logistics, assistance and an exciting scientific environment for the Mediterranean NAOS activity. C. Migon, O. Pasqueron de Fommervault, A. Dufour and the Plateforme de Chimie Analytique (PACEM) of MIO are acknowledged for their measurements, analyses and interpretation of $\mathrm{NO}_{3}$ data in the Mediterranean Sea. D. Lefevre is acknowledged for his help with winkler oxygen titration in the Mediterranean Sea. M. Ribera d'Alcalà, C. Estournel, P. Rayet, H. Lavigne, N. Mayot, and L. Legendre are acknowledged for their useful comments and fruitful discussions on the Mediterranean activity of NAOS. We also thank M. Gosselin and his team for chl $a$ analyses onboard CCGS Amundsen, J. Ferland and M. H. Forget for sampling and Ultrapath analyses, J.-E. Tremblay and J. Gagnon for nutrients analysis, M. Benoit-Gagné and P. Massicote for providing daily ice charts and SST (Sea Surface Temperature) maps, and D. Dumont for advice on the choice of dropping zones for Pro-Ice floats. The CCGS Amundsen crews are warmly thanked for their assistance in the deployment of Pro-Ice floats and the CCGS Louis St Laurent crew for assistance in recovering floats. We also thank C. Schaeffer at nke instrumentation for his steady technical support. The administrative staffs at Ifremer and Sorbonne Université are also acknowledged for their invaluable support. Special warm thanks go to the administrative staff of the LOV (L. Féré, C. Poutier and I. Courtois) and to the staff of the Baleine Joyeuse. Nothing was possible without them.

\section{SUPPLEMENTARY MATERIAL}

The Supplementary Material for this article can be found online at: https://www.frontiersin.org/articles/10.3389/fmars. 2020.577408/full\#supplementary-material

Supplementary Figure 1 | Pro-ice comparison HPLC Chla/Float Chla.

Supplementary Figure 2 | pro-ice comparison Bottle Nitrate/Float Nitrate (Suna).

Supplementary Table $\mathbf{1}$ | Vertical resolution for the Pro-Ice sensors. After the first deployments, modifications were carried out essentially for the OCR acquisition layer reduced from 250 to $200 \mathrm{~m}$, except for night-casts.

Supplementary Table 2 | Number of profiles per Pro-Ice float (2016-2019).

Supplementary Table 3 | Correction coefficients of the Delayed Mode QC of Pro-Ice BGC-Argo data.

from Mercator operational system. J. Geophys. Res. Oceans 123, 8489-8507. doi: 10.1029/2018JC014528

Barbieux, M., Uitz, J., Bricaud, A., Organelli, E., Poteau, A., Schmechtig, C., et al. (2018). Assessing the variability in the relationship between the particulate backscattering coefficient and the chlorophyll a concentration from a global Biogeochemical-Argo database. J. Geophys. Res. Oceans 123, 1229-1250. doi: 10.1002/2017jc01 3030

Barbieux, M., Uitz, J., Gentili, B., de Fommervault, O. P., Mignot, A., Poteau, A., et al. (2019). Bio-optical characterization of subsurface 
chlorophyll maxima in the Mediterranean Sea from a BiogeochemicalArgo float database. Biogeosciences 16, 1321-1342. doi: 10.5194/bg-16-13212019

Berge, J., Renaud, P. E., Darnis, G., Cottier, F., Last, K., Gabrielsen, T. M., et al. (2015). In the Dark: A Review of Ecosystem Processes during the Arctic Polar Night. Prog. Oceanogr. 139, 258-271. doi: 10.1016/j.pocean.2015.08.005

Bindoff, N. L., Cheung, W. W. L., Kairo, J. G., Arístegui, J., Guinder, V. A., Hallberg, R., et al. (2019). "Changing ocean, marine ecosystems, and dependent communities," in IPCC Special Report on the Ocean and Cryosphere in a Changing Climate, eds H.-O. Pörtner, D. C. Roberts, V. Masson-Delmotte, P. Zhai, M. Tignor, E. Poloczanska, et al. (Geneva: IPCC).

Biogeochemical-Argo Planning Group (2016). The Scientific Rationale, Design and Implementation Plan for a Biogeochemical-Argo Float Array. Bermuda: Biogeochemical-Argo Planning Group.

Bittig, H., and Körtzinger, A. (2015). Tackling oxygen optode drift: near-surface and in-air oxygen optode measurements on a float provide an accurate in situ reference. J. Atmos. Oceanic Technol. 32, 1536-1543. doi: 10.1175/jtech-d-1400162.1

Bittig, H. C., Körtzinger, A., Johnson, K., Claustre, H., Emerson, S., Fennel, K., et al. (2018a). SCOR WG 142: Quality Control Procedures for Oxygen and Other Biogeochemical Sensors on Floats and Gliders. Recommendations on the Conversion Between Oxygen Quantities for Bio-Argo Floats and Other Autonomous Sensor Platforms. Plouzane: Ifremer.

Bittig, H. C., Körtzinger, A., Neill, C., van Ooijen, E., Plant, J. N., Hahn, J., et al. (2018b). Oxygen optode sensors: principle, characterization, calibration, and application in the ocean. Front. Mar. Sci. 4:429. doi: 10.3389/fmars.2017.00429

Bittig, H. C., Steinhoff, T., Claustre, H., Fiedler, B., Williams, N. L., Sauzède, R., et al. (2018c). An alternative to static climatologies: robust estimation of open ocean $\mathrm{co} 2$ variables and nutrient concentrations from T. Front. Mar. Sci. 5:328. doi: $10.3389 /$ fmars.2018.00328

Bittig, H. C., Maurer, T. L., Plant, J. N., Wong, A. P., Schmechtig, C., Claustre, H., et al. (2019). A BGC-Argo guide: Planning, deployment, data handling and usage. Front. Mar. Sci. 6:502. doi: 10.3389/fmars.2019.00502

Blanke, B., Arhan, M., Madec, G., and Roche S. (1999). Warm water paths in the equatorial Atlantic as diagnosed with a general circulation model. J. Phys. Ocean. 29, 2753-2768.

Boss, E., Swift, D., Taylor, L., Brickley, P., Zaneveld, R., Riser, S., et al. (2008). Observations of pigment and particle distributions in the western North Atlantic from an autonomous float and ocean color satellite. Limnol. Oceanogr. $52,112-122$

Bosse, A., Testor, P., Mayot, N., Prieur, L., D’Ortenzio, F., Mortier, L., et al. (2017). A submesoscale coherent vortex in the Ligurian Sea: From dynamical barriers to biological implications. J. Geophys. Res. Oceans 122, 6196-6217. doi: 10.1002/2016JC012634

Boutin, J., Vergely, J. L., Marchand, S., D’Amico, F., Hasson, A., Kolodziejczyk, N., et al. (2018). New SMOS Sea Surface Salinity with reduced systematic errors and improved variability. Remote Sens. Environ. 214, 115-134. doi: 10.1016/j. rse.2018.05.022

Brasseur, P., Gruber, N., Barciela, R., Brander, K., Doron, M., El Moussaoui, A., et al. (2009). Integrating biogeochemistry and ecology into ocean data assimilation systems. Oceanography 22, 206-215. doi: 10.5670/oceanog.20 09.80

Bricaud, A., Babin, M., Claustre, H., Ras, J., and Tieche, F. (2010). Light absorption properties and absorption budget of Southeast Pacific waters. J. Geophys. Res. Oceans 115.

Capuano, T. A., Speich, S., Carton, X., and Laxenaire, R. (2018). Indo-atlantic exchange, mesoscale dynamics, and antarctic intermediate water. J. Geophys. Res. Oceans 123, 3286-3306. doi: 10.1002/2017JC013521

Cazenave, A., Dieng, H., Meyssignac, B., von Schuckmann, K., Decharme, B., and Berthier, E. (2014). The rate of sea level rise. Nat. Clim. Change 4, 358-361. doi: 10.1038/NCLIMATE2159

Claustre, H., Johnson, K. S., and Takeshita, Y. (2020). Observing the global ocean with biogeochemical-argo. Annu. Rev. Mar. Sci. 12, 11.1-11.26. doi: 10.1146/ annurev-marine-010419-010956

Cossarini, G., Mariotti, L., Feudale, L., Mignot, A., Salon, S., Taillandier, V., et al. (2019). Towards operational 3D-Var assimilation of chlorophyll Biogeochemical-Argo float data into a biogeochemical model of the
Mediterranean Sea. Ocean Model. 133, 112-128. doi: 10.1016/j.ocemod.2018. 11.005

Cravatte, S., Kestenare, E., Marin, F., Dutrieux, P., and Firing, E. (2017). Subthermocline and intermediate zonal currents in the tropical pacific ocean: paths and vertical structure. J. Phys. Oceanogr. 47, 2305-2324. doi: 10.1175/ JPO-D-17-0043.1

Daniault, N., Mercier, H., Lherminier, P., Sarafanov, A., Falina, A., Zunino, P., et al. (2016). The northern North Atlantic Ocean mean circulation in the early 21 st century. Prog. Oceanogr. 146, 142-158. doi: 10.1016/j.pocean.2016.06.007

De Fommervault, P. O., D’Ortenzio, F., Mangin, A., Serra, R., Migon, C., Claustre, H., et al. (2015a). Seasonal variability of nutrient concentrations in the Mediterranean Sea: Contribution of Bio-Argo floats. J. Geophys. Res. Oceans $120,8528-8550$.

De Fommervault, P. O., Migon, C., D’Alcalà, M. R., and Coppola, L. (2015b). Temporal variability of nutrient concentrations in the northwestern Mediterranean sea (DYFAMED time-series station). Deep Sea Res. I Oceanogr. Res. Pap. 100, 1-12. doi: 10.1016/j.dsr.2015.02.006

De Lavergne, C., Madec, G., Capet, X., Maze, G., and Roquet, F. (2016). Getting to the bottom of the ocean. Nat. Geosci. 9, 857-858. doi: 10.1038/ngeo2850

De Madron, X., Guieu, C., Sempere, R., Conan, P., Cossa, D., D’Ortenzio, F., et al. (2011). Marine ecosystems' responses to climatic and anthropogenic forcings in the Mediterranean. Prog. Oceanogr. 91, 97-166.

De Madron, X., Houpert, L., Puig, P., Sanchez-Vidal, A., Testor, P., Bosse, A., et al. (2013). Interaction of dense shelf water cascading and open-sea convection in the northwestern Mediterranean during winter 2012. Geophys. Res. Lett. 40, 1379-1385. doi: 10.1002/grl.50331

Desbruyères, D. G., Purkey, S. G., McDonagh, E. L., Johnson, G. C., and King, B. A. (2016). Deep and abyssal ocean warming from 35 years of repeat hydrography. Geophys. Res. Lett. 43, 356-310. doi: 10.1002/2016GL070413

Dieng, H. B., Cazenave, A., Meyssignac, B., and Ablain, M. (2017). New estimate of the current rate of sea level rise from a sea level budget approach. Geophys. Res. Lett. 44, 3744-3751. doi: 10.1002/2017GL073308

D'Ortenzio, F., and d'Alcala, M. R. (2009). On the trophic regimes of the Mediterranean Sea: a satellite analysis. Biogeosciences 6, 139-148. doi: 10.5194/ bg-6-139-2009

D’Ortenzio, F., Lavigne, H., Le Reste, S., Besson, F., Claustre, H., Coppola, L., et al. (2014). Observing mixed layer depth, nitrates and chlorophyll concentrations in the North Western Mediterranean: a combined satellite and NO3 profiling floats experiment. Geophys. Res. Lett. 41, 6443-6451. doi: 10. 1002/2014GL061020

D’Ortenzio, F., Ribera D’Alcala, M., Prieur, L., Taillandier, V., Gacic, M., Civitarese, G., et al. (2012). Roadmap for the Deployment Decision of the NAOS Bio-Argo Mediterranean Floats. Available online at: http://en.naos-equipex.fr/content/ download/65505/877517/file/ Roadmap_Bio_Argo_NAOS_dec2012-1.pdf

D’Ortenzio, F., Taillandier, V., Claustre, H., Prieur, L. M., Leymarie, E., Mignot, A., et al. (2020). Biogeochemical argo: the test case of the NAOS mediterranean array. Front. Mar. Sci. 7:120. doi: 10.3389/fmars.2020.00120

Estournel, C., Testor, P., Taupier-Letage, I., Bouin, M.-N., Coppola, L., Durand, P., et al. (2016). HyMeX-SOP2: The field campaign dedicated to dense water formation in the northwestern Mediterranean. Oceanography 29, 196-206. doi: 10.5670/oceanog.2016.94

Euro-Argo ERIC (2017). Strategy for evolution of Argo in Europe. EA-2016-ERICSTRAT. Brest: Euro-Argo ERIC.

Freeland, H. J., Roemmich, D., Garzoli, S. L., Le Traon, P. Y., Ravichandran, M., Riser, S., et al. (2010). Argo - A Decade of Progress. OceanObs'09: Sustained Ocean Observations and Information for Society (Vol. 2), Venice, Italy, 21-25 September 2009. Available online at: https://archimer.ifremer.fr/doc/00029/14038/

Gallian, M., and Thierry, V. (2018). Delayed-Mode Quality Control of Dissolved Oxygen Concentration Measured by Argo Floats in the North-Atlantic with LOCODOX - Floats Deployed in 2012, 2014, 2015, 2016 and 2017. doi: 10.13155/ 58314

Gasparin, F., Hamon, M., Rémy, E., and Le Traon, P. Y. (2019). How deep Argo will improve the deep ocean in an ocean reanalysis. J. Clim. 33, 77-94. doi: 10.1175/JCLI-D-19-0208.1

Grasshoff, K., Ehrhardt, M., Kremling, K., and Anderson, L. G. (1999). Methods of Seawater Analysis. 3rd, Completely Revised and Extended Edition. Hoboken, NJ: Weinheim Wiley-VCH. 
Gruber, N., Doney, S., Emerson, S., Gilbert, D., Kobayashi, T., Körtzinger, A., et al. (2007). The ARGO-Oxygen Program-A White Paper to Promote the Addition of Oxygen Sensors to the International Argo Float Program. Bermuda: Argo Steering Committee.

Houpert, L., Durrieu de Madron, X., Testor, P., Bosse, A., d'Ortenzio, F., Bouin, M.-N., et al. (2016). Observations of open-ocean deep convection in the northwestern $\mathrm{M}$ editerranean $\mathrm{S}$ ea: Seasonal and interannual variability of mixing and deep water masses for the 2007-2013 Period. J. Geophys. Res. Oceans 121, 8139-8171. doi: 10.1002/2016jc011857

Johnson, G. C., Lyman, J. M., and Purkey, S. G. (2015). Informing deep Argo array design using Argo and full-depth hydrographic section data. J. Atmos. Ocean. Technol. 32, 2187-2198. doi: 10.1175/JTECH-D-15-0139.1

Johnson, K., Pasqueron De Fommervault, O., Serr, R., D’Ortenzio, F., Schmechtig, C., Claustre, H., et al. (2018). Processing Bio-Argo Nitrate Concentration at the DAC Level. Version 1.1, March 3rd 2018. Plouzane: IFREMER for Argo Data Management.

Johnson, K. S., Plant, J. N., Coletti, L. J., Jannasch, H. W., Sakamoto, C. M., Riser, S. C., et al. (2017). Biogeochemical sensor performance in the SOCCOM profiling float array. J. Geophys. Res. Oceans 122, 6416-6436. doi: 10.1002/ 2017JC012838

Johnson, K. S., Plant, J. N., Riser, S. C., and Gilbert, D. (2015). Air oxygen calibration of oxygen optodes on a profiling float array. J. Atmos. Ocean. Technol. 32, 2160-2172. doi: 10.1175/JTECH-D-15-0101.1

Johnson, K. S., Riser, S. C., and Karl, D. M. (2010). Nitrate supply from deep to near-surface waters of the North Pacific subtropical gyre. Nature 465, $1062-$ 1065. doi: 10.1038/nature09170

Keeling, R. F., Körtzinger, A., and Gruber, N. (2010). Ocean deoxygenation in a warming World. Annu. Rev. Mar. Sci. 2, 199-229. doi: 10.1146/annurev. marine.010908.163855

Kessouri, F., Ulses, C., Estournel, C., Marsaleix, P., D’Ortenzio, F., Severin, T., et al. (2018). Vertical mixing effects on phytoplankton dynamics and organic carbon export in the western Mediterranean Sea. J. Geophys. Res. Oceans 123, 1647-1669. doi: 10.1002/2016jc012669

Kessouri, F., Ulses, C., Estournel, C., Marsaleix, P., Severin, T., Pujo-Pay, M., et al. (2017). Nitrogen and phosphorus budgets in the Northwestern mediterranean deep convection region. J. Geophys. Res. Oceans 122, 9429-9454. doi: 10.1002/ 2016)C012665

Körtzinger, A., Schimanski, J., and Send, U. (2005). High quality oxygen measurements from profiling floats: a promising new technique. J. Atmos. Oceanic Technol. 22, 302-308. doi: 10.1175/jtech1701.1

Lagunas, J., Marec, C., Leymarie, E., Penkerc'h, C., Rehm, E., Desaulniers, P., et al. (2018). "Sea-ice detection for autonomous underwater vehicles and oceanographic lagrangian platformsby continuous-wave laser polarimetry," in Proceedings of the Ocean Sensing and Monitoring X in SPIE, Washinhton, DC.

Lavigne, H., D’Ortenzio, F., Migon, C., Claustre, H., Testor, P., Ribera d'Alcalà, M., et al. (2013). Enhancing the comprehension of mixed layer depth control on the Mediterranean phytoplankton phenology. J. Geophys. Res. Oceans 118, 3416-3430. doi: 10.1002/jgrc.20251

Lavigne, H., D'Ortenzio, F., Ribera D'Alcalà, M., Claustre, H., Sauzède, R., and Gacic, M. (2015). On the vertical distribution of the chlorophyll a concentration in the Mediterranean Sea: a basin-scale and seasonal approach. Biogeosciences 12, 5021-5039. doi: 10.5194/bg-12-5021-2015

Le Reste, S., Dutreuil, V., André, X., Thierry, V., Renaut, C., Le Traon, P.-Y., et al. (2016). «Deep-Arvor»: A new profiling float to extend the Argo observations down to $4000 \mathrm{~m}$ depth. J. Atmos. Oceanic Technol. 23, 1039-1055. doi: 10.1175/ JTECH-D-15-0214.1

Le Traon, P. Y. (2013). From satellite altimetry to Argo and operational oceanography: three revolutions in oceanography. Ocean Sci. 9, 901-915. doi: 10.5194/os-9-901-2013

Le Traon, P. Y., Reppucci, A., Fanjul, E. A., Aouf, L., Behrens, A., Belmonte, M., et al. (2019). From observation to information and users: the copernicus marine service perspective. Front. Mar. Sci. 6:234. doi: 10.3389/fmars.2019.00234

Lebrun, M., Vancoppenolle, M., Madec, G., and Massonnet, F. (2019). Arctic seaice-free season projected to extend into autumn. Cryosphere 13, 79-96. doi: 10.5194/tc-13-79-2019

Lellouche, J.-M., Greiner, E., Le Galloudec, O., Garric, G., Regnier, C., Drevillon, M., et al. (2018). Recent updates to the Copernicus Marine Service global ocean monitoring and forecasting real-time $1 / 12^{\circ}$ high-resolution system. Ocean Sci. 14, 1093-1126. doi: 10.5194/os-14-1093-2018

Leymarie, E., Penkerc'h, C., Vellucci, V., Lerebourg, C., Antoine, D., Boss, E., et al. (2018). " ProVal: a new autonomous profiling float for high quality radiometric measurements ». Front. Mar. Sci. 5:437. doi: 10.3389/fmars.2018.00437

Leymarie, E., Poteau, A., André, X., Besson, F., Brault, P., Claustre, H., et al. (2013). Development and Validation of the New ProvBioII Float. Silver Spring, MD: NOAA.

Lherminier, P., Mercier, H., Gourcuff, C., Alvarez, M., Bacon, S., and Kermabon, C. (2007). Transports across the 2002 Greenland-Portugal Ovide section and comparison with 1997. J. Geophys. Res. Oceans 112, 26-45. doi: 10.1029/ 2006JC003716

Lindsay, R., and Schweiger, A. (2015). Arctic sea ice thickness loss determined using subsurface, aircraft, and satellite observations. Cryosphere 9, 269-283. doi: 10.5194/tc-9-269-2015

Llovel, W., Willis, J., and Landerer, F. (2014). Deep-ocean contribution to sea level and energy budget not detectable over the past decade. Nat. Clim. Change 4, 1031-1035. doi: 10.1038/nclimate2387

Lozier, M. S., Li, F., Bacon, S., Bahr, F., Bower, A. S., Cunningham, S. A., et al. (2019). A sea change in our view of overturning in the subpolar North Atlantic. Science 363, 516-521. doi: 10.1126/science.aau6592

Malanotte-Rizzoli, P., Artale, V., Borzelli-Eusebi, G. L., Brenner, S., Civitarese, G. Crise, A., et al. (2014). Physical forcing and physical/biochemical variability of the Mediterranean Sea: a review of unresolved issues and directions for future research. Ocean Sci. 10, 281-322. doi: 10.5194/os-10-281-2014

Mayot, N., D’Ortenzio, F., Taillandier, V., Prieur, L., Pasqueron de Fommervault, O., Claustre, H., et al. (2017a). Physical and biogeochemical controls of the phytoplankton blooms in North-Western Mediterranean Sea: A multiplatform approach over a complete annual cycle (2012-2013 DEWEX experiment). J. Geophys. Res. Oceans 122, 9999-10019. doi: 10.1002/2016jc012052

Mayot, N., D’Ortenzio, F., Uitz, J., Gentili, B., Ras, J., Vellucci, V., et al. (2017b). Influence of the phytoplankton community structure on the spring and annual primary production in the North-Western Mediterranean Sea. J. Geophys. Res. Oceans 122, 9918-9936. doi: 10.1002/2016jc012668

Maze, G., Mercier, H., Thierry, V., Memery, L., Morin, P. and Perez, F. F., (2012). Mass, nutrient and oxygen budgets for the northeastern Atlantic Ocean. Biogeosciences 9, 4099-4113. doi: 10.5194/bg-9-4099-2012

Mercier, H., Lherminier, P., Sarafanov, A., Gaillard, F., Daniault, N., Desbruyeres, D., et al. (2015). Variability of the meridional overturning circulation at the Greenland-Portugal OVIDE section from 1993 to 2010. Prog. Oceanogr. 132, 250-261. doi: 10.1016/j.pocean.2013.11.001

Mignot, A., D’Ortenzio, F., Taillandier, V., Cossarini, G., and Salon, S. (2019). Quantifying observational errors in biogeochemical-argo oxygen, nitrate, and chlorophyll a concentrations. Geophys. Res. Lett. 46, 4330-4337. doi: 10.1029/ 2018GL080541

Nguyen, A. T., Heimbach, P., Garg, V. V., Ocaña, V., Lee, C., and Rainville, L. (2020). Impact of synthetic arctic argo-type floats in a coupled ocean-sea ice state estimation framework. J. Atmos. Oceanic Technol. 37, 1477-1495. doi: 10.1175/JTECH-D-19-0159.1

Notz, D., and Stroeve, J. (2018). The trajectory towards a seasonally ice-free arctic Ocean. Curr. Clim. Change Rep. 4, 407-416. doi: 10.1007/s40641-018-0113-2

Organelli, E., Claustre, H., Bricaud, A., Barbieux, M., Uitz, J., D’Ortenzio, F., et al. (2017). Bio-optical anomalies in the world's oceans: An investigation on the diffuse attenuation coefficients for downward irradiance derived from Biogeochemical Argo float measurements. J. Geophys. Res. Oceans 122, 3543 3564. doi: 10.1002/2016jc012629

Parsons, T. R., Maita, Y., and Lalli, C. M. (1984). A Manual of Chemical and Biological Methods for Seawater Analysis. Oxford: Pergamon Press.

Petit, T., Mercier, H., and Thierry, V. (2018). First direct estimates of volume and water mass transports across the reykjanes ridge. J. Geophys. Res. Oceans 123, 6703-6719. doi: 10.1029/2018JC013999

Picheral, M., Guidi, L., Stemmann, L., Karl, D. M., Iddaoud, G., and Gorsky, G. (2010). The underwater vision profiler 5: an advanced instrument for high spatial resolution studies of particle size spectra and zooplankton. Limnol. Oceanogr. Methods 8, 462-473. doi: 10.4319/lom.2010.8.462

Piron, A., Thierry, V., Mercier, H., and Caniaux, G. (2016). Observation of basin-scale deep convection in the Irminger Sea with Argo floats in the 
2011-2012 winter. Deep Sea Res. Part I 109, 76-90. doi: 10.1016/j.dsr.2015. 12.012

Piron, A., Thierry, V., Mercier, H., and Caniaux, G. (2017). Gyre-scale deep convection in the subpolar North Atlantic Ocean during winter 2014-2015. Geophys. Res. Lett. 44, 1439-1447. doi: 10.1002/2016GL07 1895

Poulain, P. M., Barbanti, R., Font, J., Cruzado, A., Millot, C., Gertman, I., et al. (2007). MedArgo: a drifting profiler program in the Mediterranean Sea. Ocean Sci. 3, 379-395. doi: 10.5194/os-3-379-2007

Prieur, L., D'Ortenzio, F., Taillandier, V., and Testor, P. (2020). "Physical Oceanography of the Ligurian Sea," in The Mediterranean Sea in the Era of Global Change 1: 30 Years of Multidisciplinary Study of the Ligurian Sea, eds C. Migon, P. Nival, and A. Sciandra (Hoboken, NJ: Wiley), 49-78. doi: 10.1002/ 9781119706960.ch3

Prieur, L., Raimbault, P., and Testor, P. (2014). Observing mixed layer depth, nitrates and chlorophyll concentrations in the North Western Mediterranean: a combined satellite and NO3 profiling floats experiment. Geophys. Res. Lett. 41, 6443-6451. doi: 10.1002/2014GL061020

Racapé, V., Thierry, V., Mercier, H., and Cabanes, C. (2019). ISOW spreading and mixing as revealed by deep-argo floats launched in the charlie-gibbs fracture zone. J. Geophys. Res. Oceans 124, 6787-6808. doi: 10.1029/2019JC015040

Randelhoff, A., Holding, J., Janout, M., Kristian Sejr, M., Babin, M., Tremblay, J., et al. (2020a). « Pan-arctic ocean primary production constrained by turbulent nitrate fluxes ». Front. Mar. Sci. 7:150. doi: 10.3389/fmars.2020.00150

Randelhoff, A., Lacour, L., Marec, C., Leymarie, E., Lagunas, J., Xing, X., et al. (2020b). Arctic mid-winter phytoplankton growth revealed by autonomous profilers. Sci. Adv. 6:eabc2678.

Randelhoff, A., Oziel, L., Massicotte, P., Bécu, G., Gali, M., Lacour, L., et al. (2019). The evolution of light and vertical mixing across a phytoplankton ice-edge bloom. Elemen. Sci. Anthropocene 7:20. doi: 10.1525/elementa.357

Ras, J., Claustre, H., and Uitz, J. (2008). Spatial variability of phytoplankton pigment distributions in the Subtropical South Pacific Ocean: comparison between in situ and predicted data. Biogeosciences 5, 353-369. doi: 10.5194/ bg-5-353-2008

Riser, S. C., Freeland, H. J., Roemmich, D., Wijffels, S., Troisi, A., Belbeoch, M., et al. (2016). Fifteen years of ocean observations with the global Argo array. Nat. Clim. Change 6, 145-153. doi: 10.1038/nclimate2872

Riser, S. C., and Johnson, K. S. (2008). Net production of oxygen in the subtropical ocean. Nature 451, 323-325. doi: 10.1038/nature06441

Roemmich, D., Alford, M. H., Claustre, H., Johnson, K., King, B., Moum, J., et al. (2019). On the future of Argo: A global, full-depth, multi-disciplinary array. Front. Mar. Sci. 6:28. doi: 10.3389/fmars.2019.00439

Roesler, C., Uitz, J., Claustre, H., Boss, E., Xing, X., Organelli, E., et al. (2017). Recommendations for obtaining unbiased chlorophyll estimates from in situ chlorophyll fluorometers: A global analysis of WET Labs ECO sensors. Limnol. Oceanogr. Methods 15, 572-585. doi: 10.1002/lom3.10185

Sauzède, R., Bittig, H. C., Claustre, H., Pasqueron de Fommervault, O., Gattuso, J.-P., Legendre, L., et al. (2017). Estimates of water-column nutrient concentrations and carbonate system parameters in the global ocean: A novel approach based on neural networks. Front. Mar. Sci. 4:128. doi: 10.3389/fmars. 2017.00128

Sauzède, R., Claustre, H., Jamet, C., Uitz, J., Ras, J., Mignot, A., et al. (2015). Retrieving the vertical distribution of chlorophyll a concentration and phytoplankton community composition from in situ fluorescence profiles: A method based on a neural network with potential for global-scale applications. J. Geophys. Res. Oceans 120, 451-470. doi: 10.1002/2014jc01 0355

Sauzède, R., Claustre, H., Uitz, J., Jamet, C., Dall'Olmo, G., D’Ortenzio, F., et al. (2016). A neural network-based method for merging ocean color and Argo data to extend surface bio-optical properties to depth: Retrieval of the particulate backscattering coefficient. J. Geophys. Res. Oceans 121, 2552-2571. doi: 10. 1002/2015jc011408

Schmechtig, C., Poteau, A., Claustre, H., D’Ortenzio, F., and Boss, E. (2015). Processing bio-Argo Chlorophyll-A Concentration at the DAC Level. Plouzane: Ifremer for Argo Data Management.

Schmechtig, C., Poteau, A., Claustre, H., D’Ortenzio, F., DallOlmo, G., and Boss, E. (2018). Processing BGC-Argo Particle Backscattering at the DAC Level. Plouzane: Ifremer for Argo Data Management.
Schmechtig, C., Thierry, V., and The Bio Argo Team (2016). Argo Quality Control Manual for Biogeochemical Data. Plouzane: Ifremer for Argo Data Management.

Sévellec, F., Verdiére, A. C. D., and Ollitrault, M. (2017). Evolution of intermediate water masses based on argo float displacements. J. Phys. Oceanogr. 47, 15691586. doi: 10.1175/jpo-d-16-0182

Siokou-Frangou, I., Christaki, U., Mazzocchi, M., Montresor, M., Ribera d'Alcalà, M., Vaqué, D., et al. (2010). Plankton in the open Mediterranean Sea: a review. Biogeosciences 7, 1543-1586. doi: 10.5194/bg-7-1543-2010

Sloyan, B. M., Wanninkhof, R., Kramp, M., Johnson, G. C., Talley, L. D., Tanhua, T., et al. (2019). The global ocean ship-based hydrographic investigations program (GO-SHIP): a platform for integrated multidisciplinary ocean science. Front. Mar. Sci. 6:445. doi: 10.3389/fmars.2019.00445

Smith, G. C., Allard, R., Babin, M., Bertino, L., Chevallier, M., Corlett, G., et al. (2019). «Polar ocean observations: a critical gap in the observing system and its effect on environmental predictions from hours to a season ». Front. Mar. Sci. 6:429. doi: 10.3389/fmars.2019.00429

Smith, G. C., Roy, F., Reszka, M., Surcel Colan, D., He, Z., Deacu, D., et al. (2016). Sea ice forecast verification in the canadian global ice ocean prediction system. J. R. Meteorol. Soc. 142, 659-671. doi: 10.1002/qj.2555

Taillandier, V., Wagener, T., D'Ortenzio, F., Mayot, N., Legoff, H., Ras, J., et al. (2018). Hydrography and biogeochemistry dedicated to the Mediterranean BGC-Argo network during a cruise with RV Tethys 2 in May 2015. Earth System Science Data 10, 627-641. doi: 10.5194/essd-10-6272018

Takeshita, Y., Martz, T. R., Johnson, K. S., Plant, J. N., Gilbert, D., Riser, S. C., et al. (2013). A climatology-based quality control procedure for profiling float oxygen data. J. Geophys. Res. Oceans 118, 5640-5650. doi: 10.1002/jgrc.2 0399

Terzić, E., Lazzari, P., Organelli, E., Solidoro, C., Salon, S., d'Ortenzio, F., et al. (2019). Merging bio-optical data from Biogeochemical-Argo floats and models in marine biogeochemistry. Biogeosciences 16, 2527-2542. doi: 10.5194/bg-162527-2019

Testor, P., Bosse, A., and Houpert, L. F. (2018). Multi-scale observations of deep convection in the northwestern Mediterranean Sea during winter 2012-2013 from a multi-platform approach. J. Geophys. Res. Oceans 123, 1745-1776.

Thierry, V., Bittig, H., Gilbert, D., Kobayashi, T., Kanako, S., and Schmid, C. (2018a). Processing Argo oxygen data at the DAC level. Plouzane: Ifremer for Argo Data Management.

Thierry, V., Bittig, H., and The Argo-Bc Team (2018b). Argo Quality Control Manual for Dissolved Oxygen Concentration. Plouzane: Ifremer for Argo Data Management.

Thierry, V., Brion, E., Gallian, M., Reynaud, T., Bouinot, T., Lagadec, C., et al. (2020). LOCODOX : a Software for Argo Oxygen data correction - User Manual. Available online at: https://archimer.ifremer.fr/doc/00630/74190/. The software can be downloaded at https://github.com/treynaud/LOCODOX-V3.4

Turpin, V., Remy, E., and Le Traon, P. Y. (2016). How essential are Argo observations to constrain a global ocean data assimilation system ? Ocean Sci. 12, 257-274. doi: 10.5194/os-12-257-2016

Volpe, G., Santoleri, R., Vellucci, V., Ribera d'Alcalà, M., Marullo, S., and D'Ortenzio, F. (2007). The colour of the Mediterranean Sea: global versus regional bio-optical algorithms evaluation and implication for satellite chlorophyll estimates. Remote Sens. Environ. 107, 625-638. doi: 10.1016/j.rse. 2006.10.017

Von Schuckmann, K., Palmer, M. D., Trenberth, K. E., Cazenave, A., Chambers, D., Champollion, N., et al. (2016). Earth's energy imbalance: an imperative for monitoring. Nat. Clim. Change 26, 138-144.

Willmes, S., and Heinemann, G. (2015). Sea-ice wintertime lead frequencies and regional characteristics in the arctic, 2003-2015. Remote Sens. 8:4. doi: 10.3390/ rs8010004

Wolf, M. K., Hamme, R. C., Gilbert, D., Yashayaev, I., and Thierry, V. (2018). Oxygen saturation surrounding Deep Water formation events in the Labrador sea from Argo-O2 data. Glob. Biogeochem. Cycles 32, 635-653. doi: 10.1002/ 2017GB005829

Xing, X., Briggs, N., Boss, E., and Claustre, H. (2018). Improved correction for non-photochemical quenching of in situ chlorophyll fluorescence based on a synchronous irradiance profile. Opt. Express 26, 24734-24751. doi: 10.1364/oe. 26.024734 
Xing, X., Claustre, H., Boss, E., Roesler, C., Organelli, E., Poteau, A., et al. (2017). Correction of profiles of in-situ chlorophyll fluorometry for the contribution of fluorescence originating from non-algal matter. Limnol. Oceanogr. Methods 15, $80-93$.

Xing, X., Morel, A., Claustre, H., Antoine, D., D’Ortenzio, F., Poteau, A., et al. (2011). Combined processing and mutual interpretation of radiometry and fluorimetry from autonomous profiling bio-argo floats: chlorophyll-a retrieval. J. Geophys. Res. 116:C06020. doi: 10.1029/2010JC006899

Zilberman, N., King, B., Purkey, S., Thierry, V., and Roemmich, D. (2019). Report on the 2nd Deep Argo Implementation Workshop, Hobart, May 13-15th 2019. Available online at: http://www.argo.ucsd.edu/AcDeep_Argo_ WS2.html

Zilberman, N., and Maze, G. (2015). Report on the Deep Argo Implementation Workshop. Ifremer/LPO/15-04. Available online at: https://archimer.ifremer.fr/ doc/00281/39238/.

Zunino, P., Mercier, H., and Thierry, V. (2020). Why did deep convection persist over four consecutive winters (2015-2018) Southeast of cape farewell? Ocean Sci. 16, 99-113. doi: 10.5194/os-16-992020

Conflict of Interest: The authors declare that the research was conducted in the absence of any commercial or financial relationships that could be construed as a potential conflict of interest.

Copyright $\odot 2020$ Le Traon, D’Ortenzio, Babin, Leymarie, Marec, Pouliquen, Thierry, Cabanes, Claustre, Desbruyères, Lacour, Lagunas, Maze, Mercier, Penkerc'h, Poffa, Poteau, Prieur, Racapé, Randelhoff, Rehm, Schmechtig, Taillandier, Wagener and Xing. This is an open-access article distributed under the terms of the Creative Commons Attribution License (CC BY). The use, distribution or reproduction in other forums is permitted, provided the original author(s) and the copyright owner(s) are credited and that the original publication in this journal is cited, in accordance with accepted academic practice. No use, distribution or reproduction is permitted which does not comply with these terms. 